\title{
Initiation of daytime local convection in a semi-arid region analysed with high-resolution simulations and AMMA observations
}

\author{
F. Couvreux, ${ }^{\text {a }}$ C. Rio, ${ }^{b}$ F. Guichard, ${ }^{a}$ M. Lothon, ${ }^{c}$ G. Canut, ${ }^{c}$ D. Bouniol ${ }^{\mathrm{a}}$ and A. Gounou ${ }^{\mathrm{a}}$

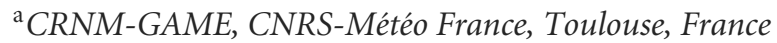 \\ ${ }^{\mathrm{b}}$ Laboratoire de Météorologie Dynamique, CNRS, Paris, France \\ 'Laboratoire d'Aérologie, Observatoire Midi-Pyrénées, CNRS, Toulouse, France
}

${ }^{\star}$ Correspondence to: F. Couvreux, Météo France, GMME, 42 av. G. Coriolis, Toulouse 31057, France.

E-mail: fleur.couvreux@meteo.fr

A modelling case study designed from observations from the African Monsoon Multidisciplinary Analysis (AMMA) is presented and discussed. It aims at investi-gating the issue of initiation of convection in a semi-arid environment. This case corresponds to the development of local daytime convection mainly controlled by boundary layer characteristics rather than by atmospheric synoptic scales. A high-resolution three-dimensional simulation is presented and extensively evalu-ated against the numerous observations available for 10 July 2006 from the AMMA campaign. The simulation, run over a domain of $100 \times 100 \mathrm{~km}$, is able to represent main boundary layer structures and processes leading to deep convection initiation as well as the formation of density currents. Sensitivity tests point to the key role of the sensible heat flux, the humidity of low to mid levels, the lapse rate at low levels and of a mesoscale ascent to initiate deep convection in those semi-arid conditions, while evaporation of precipitation is shown to play a minor role. This study thus provides a case to investigate the ability of parametrizations to handle the initiation of convection in a semi-arid environment.

Key Words: convective initiation; diurnal cycle; semi-arid conditions; shallow to deep convection transition; West African monsoon

\section{Introduction}

Current climate and Earth system models exhibit large biases in the Tropics, among them an incorrect representation of the diurnal cycle of precipitation over continents (Yang and Slingo, 2001) and a poor representation of the location, intensity distribution and diurnal cycles of precipitation in monsoon regions (Kang et al., 2002; Janowiak et al., 2007). Those two biases involve moist convection. This process operates on a large range of spatial and temporal scales and involves numerous interactions with the surface, the boundary layer turbulence, cloud microphysics and radiation. In particular, the coupling with the surface and the boundary layer turbulence occurs at a small scale and is difficult to observe. The use of modelling studies at a relatively high resolution stands as an appealing approach in order to understand and diagnose the processes at play and to improve their representation in climate and Earth system models.

Recent studies on the diurnal cycle and the transition from shallow to deep convection have focused on the wet Tropics (Khairoutdinov and Randall, 2006 (KR06 from hereon); Grabowski et al., 2006 (G06 from hereon)) or midlatitude environments (Guichard et al., 2004 (G04 from hereon)). G04 have highlighted the role of an intermediate 
shallow cumulus phase preceding deep convection initiation and moistening the middle levels. Other studies have also underlined the role of humidity in the free troposphere in shaping the development of deep convection (Chaboureau et al., 2004; Derbyshire et al., 2004; Kuang and Bretherton, 2006). Based on previous studies, the humidification of the free troposphere is one of a few variables expected to exert a major control on the transition from shallow to deep convection. Other variables notably include the lapse rate of the atmosphere (Houston and Niyogi, 2007; Wu et al., 2009 (Wu09 from hereon)) as well as boundary layer heterogeneities (Zhang and Klein, 2010), including those driven by convective outflows (KR06).

G04 emphasized difficulties for parametrizations to handle this transition with, in particular, a too fast onset of precipitation for the single-column models (SCM) in comparison to cloud-resolving models (which explicitly resolved deep convection). This was in agreement with a previous study of Betts and Jakob (2002) analysing the representation of the diurnal cycle of precipitation in the European Centre for Medium-range Weather Forecasts model. Rio et al. (2009) improved the representation of the diurnal cycle in an SCM for the G04 case by taking into account the role of boundary layer thermals in deep convection preconditioning and of cold pools generated through rain evaporation in its sustainment. However, midlatitude regions may not be representative of all conditions encountered over the globe and further studies are needed to improve our understanding of the processes that control the transition from shallow to deep convection.

This study focuses on semi-arid conditions - conditions that have been only poorly studied where, nevertheless, initiation of convection still occurs. In particular, the studied case occurred in the Sahel in West Africa. The Sahel is a semi-arid region (defined by any area with an annual precipitation rate lower than $600 \mathrm{~mm}$ per year). In this region, the rainfall is mainly generated by intense precipitating convective systems (Mathon et al., 2002). At synoptic scale, those systems are largely influenced by African easterly waves (Reed et al., 1977). Nevertheless, convection is also largely constrained by the diurnal cycle of solar radiation (Comer et al., 2007), in particular for initiation that mostly occurs in the afternoon hours (Mohr, 2004; Gounou, 2011). Surface spatial heterogeneities linked to surface moisture or temperature variability (Taylor et al., 2010) can significantly shape deep convection initiation. In particular, the role of such heterogeneities generating mesoscale circulations leading to convergence started to be analysed long ago (e.g. Wilson and Schreiber, 1986; Taylor et al., 2003). Recently, by combining different satellite products, Taylor et al. (2011) highlighted the role of the small-scale surface property gradient as a cause for initiation; in particular, convection was shown to be preferentially initiated over dry soils at a mesoscale $(100 \mathrm{~km})$ and over a warm/dry anomaly ahead of a transition from warm/cold boundaries aligned cross-wind. The Sahel, in particular before the monsoon season, is characterized by large sensible heat fluxes and low latent heat fluxes, as the soils are mostly dry (Ramier et al., 2009). In such a region, soil moisture is an important variable for initiation of convection, as shown in Alonge et al. (2007). As suggested by Findell and Eltahir (2003), over dry soils convective initiation will be favoured for initial conditions presenting a relatively large convective triggering potential (small potential temperature lapse rate), i.e. where the boundary layer will grow significantly. In such a semi-arid environment, it may be expected that knowledge resulting from studies documenting the humid Tropics and the midlatitudes cannot be directly transposed. In fact, studies of the daytime convection in semi-arid regions are very few: Takemi and Satomura (2000) analysed the mechanisms responsible for the development and maintenance of long-lived squall lines in such an environment; Takemi et al. (2006) analysed dry and moist convection in those regions using numerical simulations but they mainly focused on the emission and dust transport. The emphasis of this paper is on the triggering of local convection and subsequent development through the diurnal cycle in a semi-arid region.

Local convection is particularly difficult to observe. Satellite observations, for example, are not well suited due to their relatively coarse time and spatial resolutions. Therefore, few studies have focused on the observations of daytime local convection; among them, studies based on the IHOP_2002 experiment have documented convection initiation with observations (Weckwerth and Parsons, 2006; Weckwerth et al., 2008). Moreover, very rarely does convective initiation occur just on top of an instrumented site. In this paper, we take advantage of the very well-documented case of 10 July 2006 over Niamey (Lothon et al., 2011, L11 in the following) observed during the African Monsoon Multidisciplinary Analysis (AMMA) campaign (Redelsperger et al., 2006). This set of data is unique, as a convective system is observed during most of its life cycle at high resolution in time and space in an intensively instrumented site.

The aim of this paper is to better document the transition from boundary layer (BL) to shallow clouds, followed by the initiation of deep convection in a semiarid environment. The final goal is to set up a case to evaluate parametrizations in this semi-arid environment that is quite distinct from those encountered in wet Tropics and may not appear as favourable for the development of moist convection. We present a large-eddy simulation (LES) of the case of L11 over a large domain in order to capture the interaction between the boundary layer turbulence and moist convection. This simulation could then be used in a future step as a reference to evaluate different parametrizations in a traditional framework for comparison between SCMs and high-resolution models (see G04 for an example). The paper is structured as follows. First, the specificity of the semi-arid environment is highlighted in section 2 with the available observations. The set-up of the large-eddy simulation, its evaluation against observations and its main characteristics are then presented in section 3. Finally, the processes involved in the diurnal sequence leading to initiation of local convection are analysed in section 4 . Conclusions and perspectives are summarized in the final section.

\section{Observations of local convection initiation in a semi- arid environment}

10 July 2006 corresponds to the end of the period preceding the full monsoon season in the Sahel (Lothon et al., 2008). On this date, the monsoon flow (a cold and moist southwesterly flow in the low levels) is already present but organized mesoscale convective systems are still rare. Heating of the surface by sunlight is predominantly balanced by turbulent flux of sensible heat, as precipitation is still 


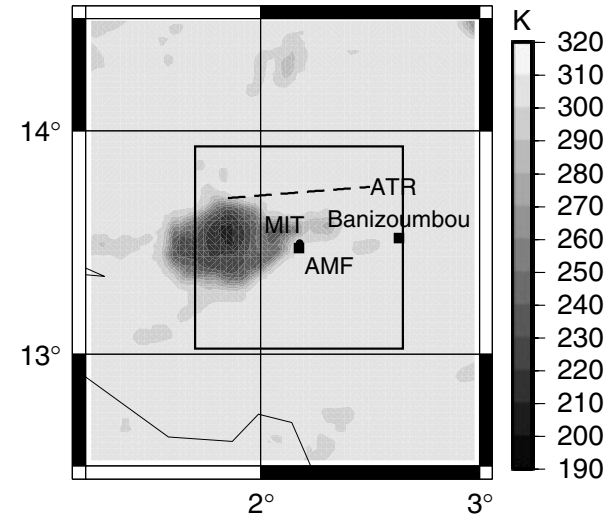

Figure 1. Brightness temperature measured from Infrared Meteosat Second Generation satellite at 1730 UTC showing locations of Banizoumbou, flight track (ATR), ARM mobile facility (AMF square) and MIT radar (MIT dot) over-plotted. The size of the domain of the reference simulation is also indicated by the black box

sparse and soil moisture very low (e.g. Miller et al., 2009). A succession of three regimes (dry convection, shallow clouds and deep convection) is observed on this day. A major interest of this case study is that the convective system is observed during most of its life cycle in the range of the MIT radar as well as the collocated ARM Mobile Facility (AMF), as illustrated in Figure 1. Those data also highlight the role of the density current in triggering new convective cells after the initiation of the system. In this section, only key features of this case, which are specific to a semi-arid environment, are highlighted (see L11 for more details). We also compare these characteristics with those of the two other cases that have been mainly used to study convection initiation: one over the ARM Southern Great Plains (G04) and the other in Amazonia during the LBA field campaign (G06) named respectively from hereon midLat and wetTropic.

Figure 2 presents the time-height series of reflectivity measured by the $94 \mathrm{GHz}$ cloud radar together with the lifting condensation level (LCL) computed from $2 \mathrm{~m}$ meteorological measurements from the AMF (blue line) and from the lowest $50 \mathrm{mb}$ average of the soundings (blue stars). For information and location on the observations used in this study, refer to Table I and Figure 1. During this day, the boundary layer grows significantly, reaching $2000 \mathrm{~m}$ at midday and more than $2500 \mathrm{~m}$ above ground level (AGL; in the following, all heights are indicated as AGL) around 1530 UTC (UTC $=$ LT-1), in agreement with UHF measurements (see Figure 3 of L11). Clouds start to form around midday, as depicted by cloud base observed by ceilometer, even though they are more numerous after 1400 UTC. In the early afternoon, shallow cumulus, in turn, starts to develop vertically, with cloud tops reaching to $6000 \mathrm{~m}$ between 1500 and 1600 UTC. Finally, a deep convective cell initiated $18 \mathrm{~km}$ east of the AMF at 1550 UTC (L11, Figure 11) and passed over the facility at 1630 UTC. This cell reaches about 12000-14000 m. Two other convective cells are also observed afterwards.

The soundings launched every $6 \mathrm{~h}$ at the AMF allow computation of different convective indexes. Figure 3 shows the time evolution of CAPE (convective available potential energy), CIN (convective inhibition), LCL and LFC (level of free convection) determined via these soundings (stars). Throughout the day, the height of the LCL significantly increases, reaching about $2000 \mathrm{~m}$ at midday, whereas the LFC remains almost stationary around $2500 \mathrm{~m}$. This leads to a large reduction of the convective inhibition in the

Table I. Characteristics of the observations used to evaluate the simulation.

\begin{tabular}{|c|c|c|c|c|}
\hline Instrument & $\begin{array}{l}\text { Measured } \\
\text { parameters used }\end{array}$ & $\begin{array}{l}\text { Time resolution/ } \\
\text { range }\end{array}$ & $\begin{array}{l}\text { Spatial resolution/ } \\
\text { range }\end{array}$ & Location \\
\hline UHF profiler & BLh & $15 \mathrm{~min} /-$ & $60 \mathrm{~m} / 6000 \mathrm{~m}$ & $\begin{array}{l}\text { Niamey }\left(13.47^{\circ} \mathrm{N},\right. \\
\left.2.18^{\circ} \mathrm{E}\right)\end{array}$ \\
\hline Radio sondes & $\begin{array}{l}\text { potential tempera- } \\
\text { ture, } \theta \text {, water vapour } \\
\text { mixing ratio } q \text {, zonal } \\
\text { and meridional wind } \\
u, v\end{array}$ & $\begin{array}{l}\text { 0530, 1130, 1730, } \\
2330 \text { UTC }\end{array}$ & $\sim 20 \mathrm{~m}$ & Niamey \\
\hline $\begin{array}{l}\text { Meteorological } \\
\text { station }\end{array}$ & $\begin{array}{l}\theta, q, u, v, \text { precipita- } \\
\text { tion, LCL }\end{array}$ & $1 \mathrm{~min} /-$ & - & Niamey \\
\hline Cloud radar/lidar & cloud base and top & $30 \mathrm{~s} /-$ & $\begin{array}{l}60 \mathrm{~m} / 20000 \mathrm{~m} \\
\text { Vertically pointing }\end{array}$ & Niamey \\
\hline Ceilometer & Cloud base & $15 \mathrm{~s}$ & - & Niamey \\
\hline Flux station & $H, \mathrm{LE}$ & $30 \mathrm{~min} /-$ & - & Niamey \\
\hline $\begin{array}{l}\text { Aircraft turbulence } \\
\text { probe }\end{array}$ & $\theta, q, w$ & $\begin{array}{l}0.04 \mathrm{~s} / 1045-1406 \\
\text { UTC }\end{array}$ & $\begin{array}{l}60 \mathrm{~km} \text { legs at } 0.1, \\
0.5,0.8 \mathrm{zi} \text {, sounding }\end{array}$ & Banizoumbou \\
\hline MIT Doppler radar & Reflectivity & $10 \mathrm{~min} /-$ & $\begin{array}{l}200 \mathrm{~m} / \\
D_{\text {clearair }}=50 \mathrm{~km} / \\
D_{\text {precip }}=250 \mathrm{~km} \\
\text { Scanning and C-band }\end{array}$ & Niamey \\
\hline MSG visible channel & Cloud presence & $15 \mathrm{~min} /-$ & $3 \mathrm{~km} / 0.9^{\circ} \times 0.7^{\circ}$ & $\begin{array}{l}1.8-2.7^{\circ} \mathrm{E} \text { and } \\
13.2-13.9^{\circ} \mathrm{N}\end{array}$ \\
\hline $\begin{array}{l}\text { MSG infrared } \\
\text { channel }\end{array}$ & Cloud top & $15 \mathrm{~min} /-$ & $3 \mathrm{~km} / 0.9^{\circ} \times 0.7^{\circ}$ & $\begin{array}{l}1.8-2.7^{\circ} \mathrm{E} \text { and } \\
13.2-^{\circ} 13.9 \mathrm{~N}\end{array}$ \\
\hline
\end{tabular}




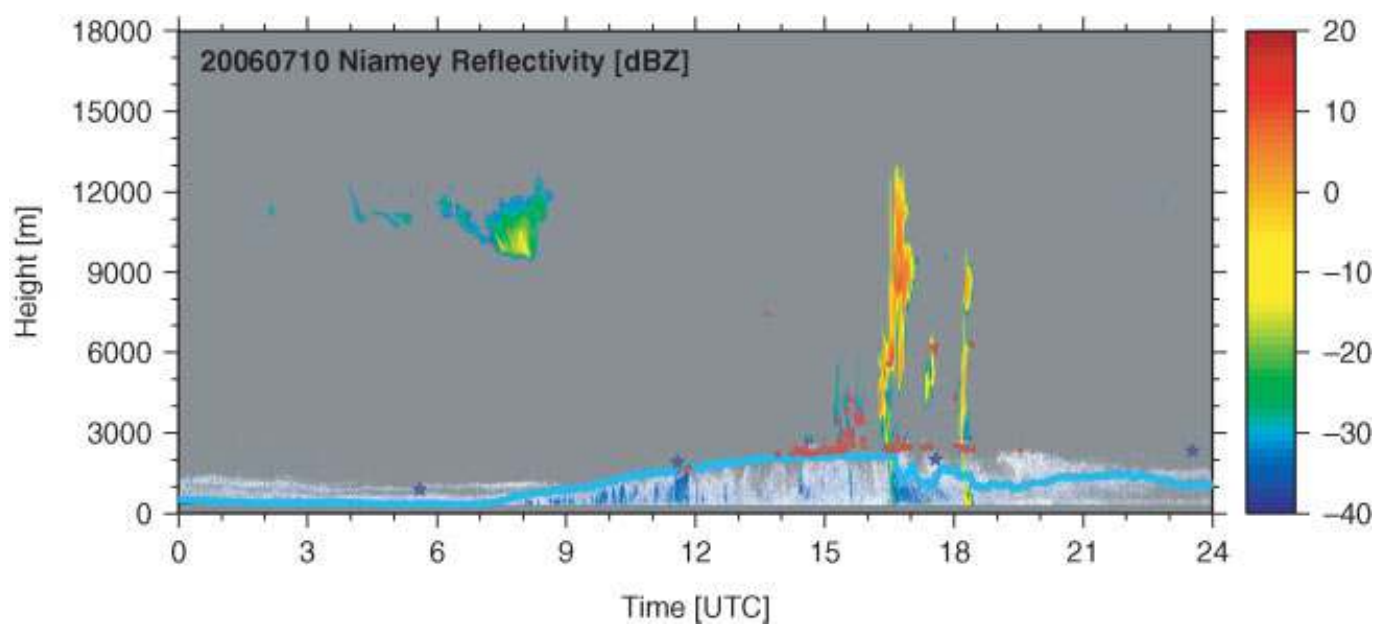

Figure 2. Time-height series of reflectivity observed by $94 \mathrm{GHz}$ cloud radar at the AMF at Niamey on 10 July 2006 (in colours) and LCL computed from $2 \mathrm{~m}$ observations of the meteorological station (cyan) and from radiosondes using the lowest $50 \mathrm{mb}$ (blue stars). Red dots indicate the cloud base determined by the ceilometer

(a)
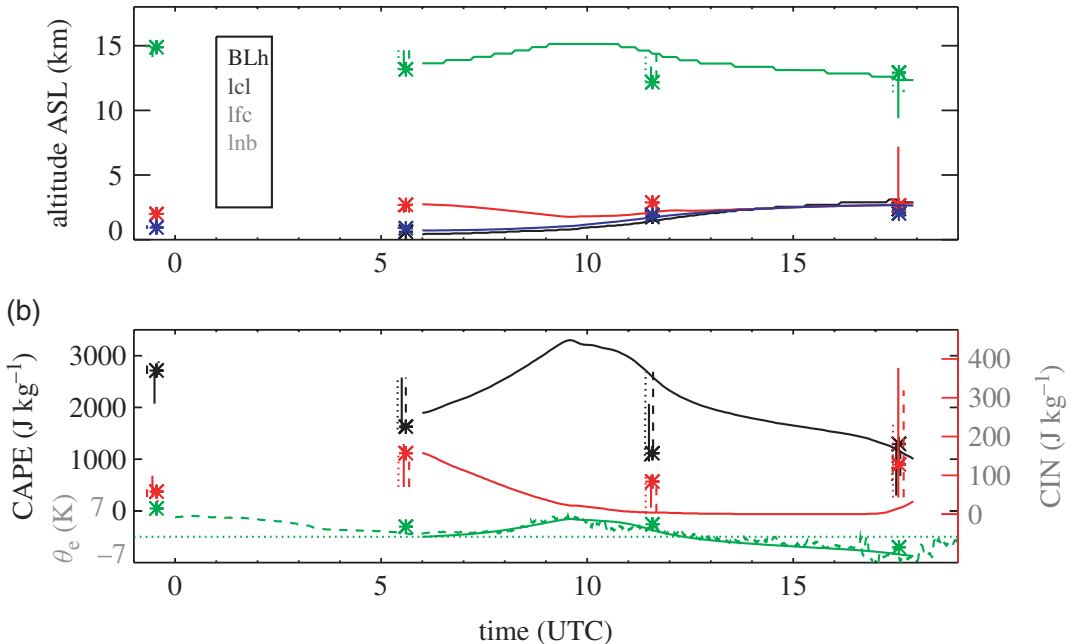

Figure 3. Time series of: (a) LCL (lcl, blue), boundary layer height (BLh, black), level of free convection (lfc, red) and level of neutral buoyancy (lnb, green); (b) CAPE (black), CIN (red) and equivalent potential temperature anomaly (green) observed by the soundings (stars) and simulated by the reference simulation (full lines). For $\theta_{\mathrm{e}}$, observations from the meteorological station are also plotted (dashed line). Bars associated with stars indicate the variability of those indices when computed from 940 to $990 \mathrm{hPa}$ with the full line for the original sounding, the dotted line when the first level is warmed by $1 \mathrm{~K}$ and the dashed line when the first level is moistened by $1 \mathrm{~g} \mathrm{~kg}^{-1}$.

morning, from 150 to $80 \mathrm{~J} \mathrm{~kg}^{-1}$ between 0530 and 1130 , linked to the important growing of the boundary layer. The CAPE decreases in the morning, suggesting that CAPE is not the control parameter for initiation of convection. This contrasts with both midLat and wetTropic cases (G04, G06), with a slowly increasing LCL and an increasing CAPE. The indexes proposed by Findell and Eltahir (2003), computed with the 0530 UTC soundings, indicate a large convective triggering potential $\left(314 \mathrm{~J} \mathrm{~kg}^{-1}\right)$, an index of stability as it corresponds to a small potential temperature lapse rate and a high low-level dryness $\left(15.23^{\circ} \mathrm{C}\right)$, an index of dryness as it corresponds to the difference between the temperature and the dew-point in the [950-825] hPa layer. Interestingly, according to these indexes, in this environment convection appears favoured over dry soil.

Surface fluxes observed at the AMF are presented in Figure 4. The sensible heat flux $(\mathrm{H})$ reaches about $350 \mathrm{~W} \mathrm{~m}^{-2}$ at midday, whereas the latent heat flux (LE) never exceeds $30 \mathrm{~W} \mathrm{~m}^{-2}$. In fact, at this time of the year, the soil is still dry and most of the solar energy is converted into sensible heat flux at the surface, as is typical of semi-arid conditions (e.g. Takemi and Satomura, 2000). The sensible heat flux is larger than those used in the midLat and wetTropic cases but the latent heat flux is much weaker. This leads to a large Bowen ratio of around 10, while the two other cases are characterized by values below 0.5 . Overall, if one assumes that the ground flux is the same fraction of the net radiation for the three cases, there is less energy input at the surface in the present case study, largely because of a higher surface albedo and temperature.

Concerning large-scale forcing, it is important to note that no African easterly wave, known largely to control convection in this region, propagates over the region during that day as shown in Janicot et al. (2008, their Figures 18(e) and 19). The pressure gradient is weak over the area during this day. Therefore, synoptic scales are not a major driver in this case.

The studied system is common over this region, as indicated by several similar systems in Figure 12 of L11. Note that those systems correspond to local convection that 
(a)

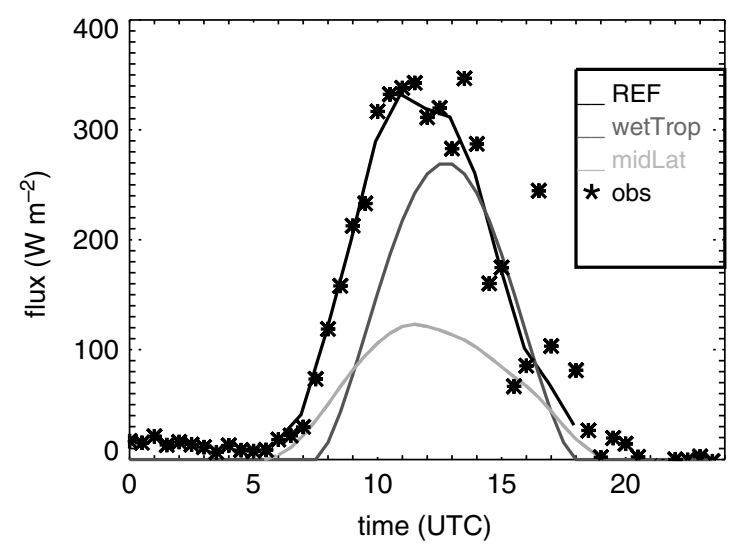

(b)

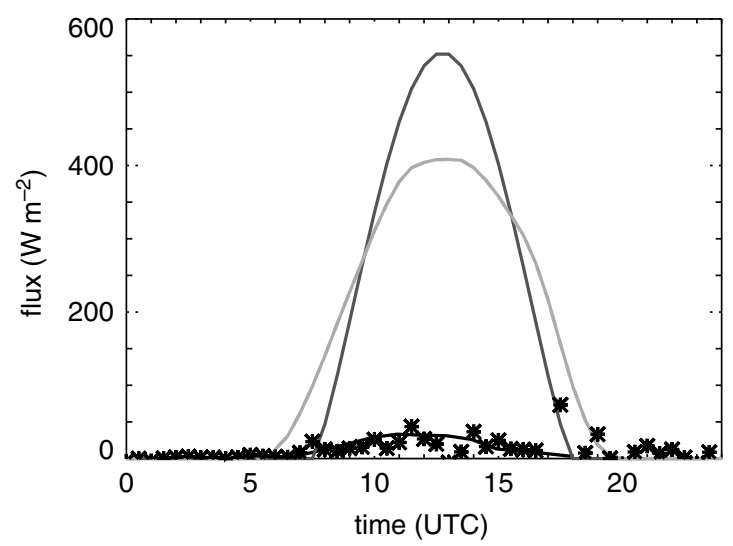

Figure 4. Time series of (a) sensible heat flux and (b) latent heat flux observed at the AMF at Niamey (stars) on 10 July 2006 and prescribed in the reference simulation (black). For comparison, the same fluxes prescribed in wetTropic and midLat are superimposed in dark and light grey respectively.

(a)

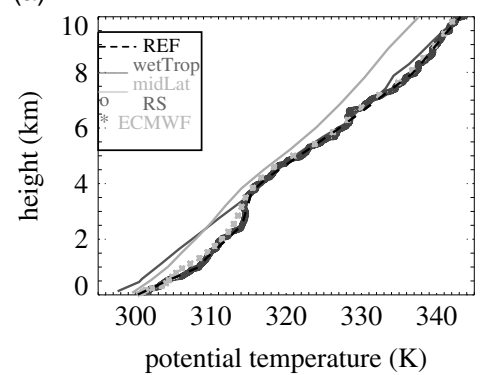

(c)

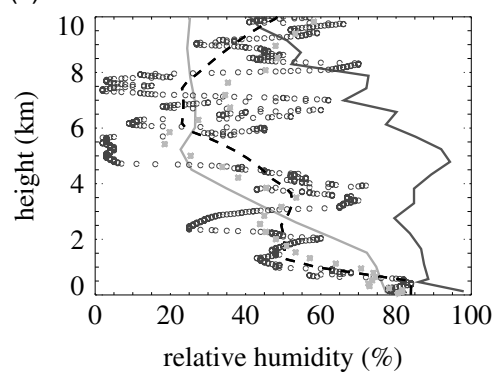

(b)

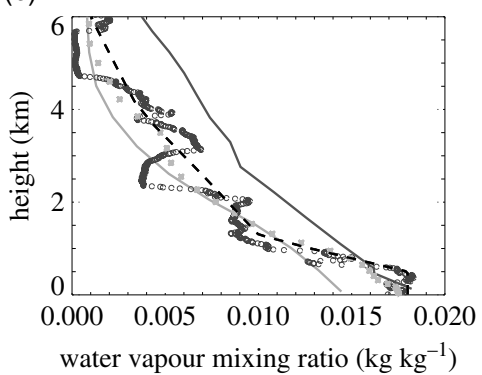

(d)

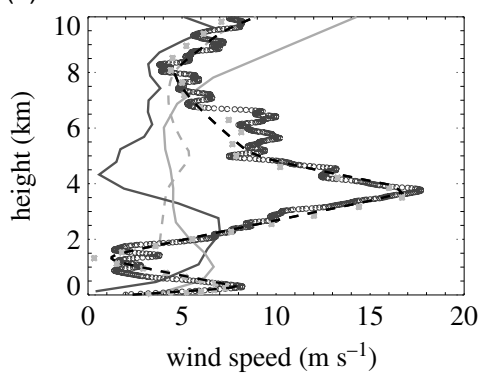

Figure 5. Vertical profile of (a) potential temperature (b) water vapour mixing ratio (for clarity this profile has been zoomed to $0-6 \mathrm{~km}$ ), (c) relative humidity and (d) wind speed used as initial profile in this case (dashed black), in wetTropic (dark grey) and in midLat (light grey). The stars correspond to the profiles from the ECMWF analyses and the dots to the soundings launched at 0530 UTC. The dashed light-grey profile in (d) corresponds to the initial wind profile for the NOAEJ simulation.

is triggered every day in this region during summer. They do not bring a lot of precipitation (among the 54 stations in a $1^{\circ} \times 1^{\circ}$ area around Niamey, only one station recorded rain - about $15 \mathrm{~mm}$ - on 10 July) and do not last for very long (a few hours). Nevertheless, they play an important role in water vapour transport, as will be illustrated in section 3.

In conclusion, this case is characteristic of semi-arid regions, with a rapid and intense growing of the LCL associated with a high cloud-base height, a large Bowen ratio indicative of a low source of moisture from the surface and a decreasing CAPE. All those conditions may not appear favourable for moist convection development and suggest a key role of the boundary layer to explain the initiation of convection as observed. These conditions are different from those observed in moist Tropics or in midlatitudes. This supports the relevance of such a study that focuses on a relatively poorly studied environment.
3. The reference simulation: set-up, evaluation and sensitivity tests

\subsection{The simulation set-up}

It is now possible to perform large-eddy simulations on relatively large domains (Wu09, KR06) and therefore to simulate explicitly the interactions between the turbulence and deep convection.

The model used here is the LES version of the nonhydrostatic model Meso- $\mathrm{NH}$, the dynamical part of which was presented by Lafore et al. (1998). The 3-D turbulence scheme (Cuxart et al., 2000) is based on Redelsperger and Sommeria (1986). It is based on a prognostic equation for sub-grid kinetic energy and incorporates the effect of thermal stratification on sub-grid fluxes through variable Prandtl and Schmidt numbers. A $100 \mathrm{~km} \times 100 \mathrm{~km} \times$ $20 \mathrm{~km}$ domain is defined. The horizontal resolution is 
(a)

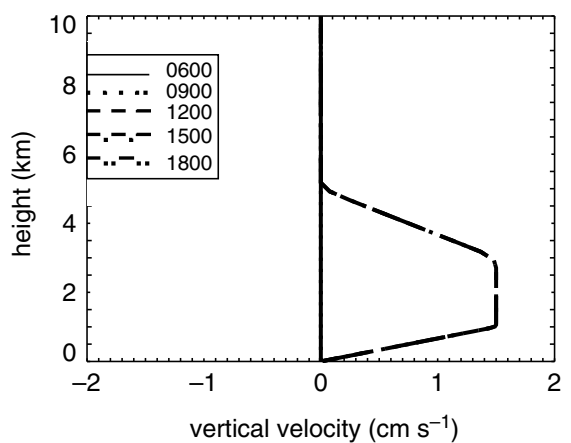

(b)

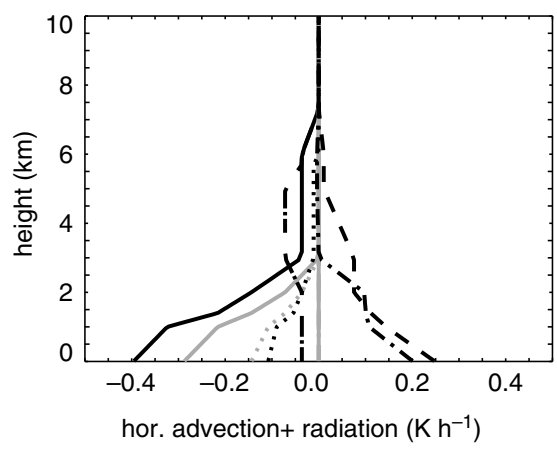

(c)

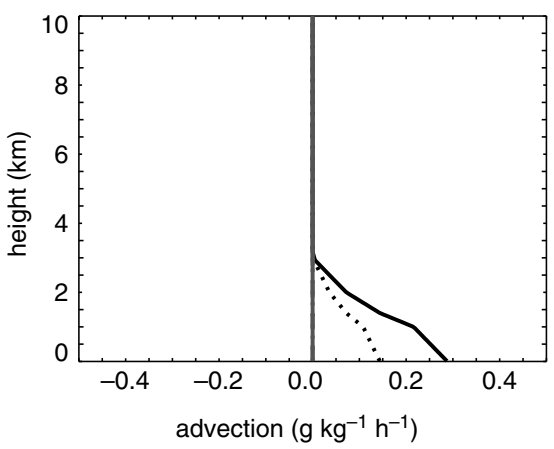

Figure 6. Vertical profile of (a) large-scale vertical velocity, (b) large-scale horizontal advection for potential temperature (corresponding to the sum of horizontal advection, indicated in grey, and the radiative tendency) and (c) large-scale horizontal advection of water vapour mixing ratio for 0600 (full line), 0900 (dotted line), 1200 (dashed line), 1500 (dot-dashed line) and 1800 UTC (long dashed line).

$500 \mathrm{~m}$. A vertical stretched grid of 118 levels is used with resolution finer than $50 \mathrm{~m}$ in the $\mathrm{BL}$ and up to $2000 \mathrm{~m}$, and coarser higher up (reaching $250 \mathrm{~m}$ at the top of the model). The lateral boundary conditions are cyclic.

The set-up of this simulation is very similar to Couvreux et al. (2005), G04 and G06. Surface fluxes inferred from observations (Figure 4) and vertical profiles of radiative tendencies derived from 1-D simulations are prescribed (Figure 6). The Coriolis effect is ignored.

The simulation starts from horizontally homogeneous conditions inferred from the observed early morning sounding, except for a random $\theta$ perturbation of $0.1 \mathrm{~K}$ at the lowest level. The simulation starts at 0600 UTC and is run until 1800 UTC. Figure 5 shows the initial profiles used in the simulation, together with sounding data, as well as initial profiles used in G04 and G06. Compared to the midLat and wetTropic cases, the vertical profile of potential temperature is warmer and characterized by a smaller lapse rate between 1000 and $5000 \mathrm{~m}$. The low-level humidity lies between wetTropic and midLat. In particular, wetTropic initial conditions are much closer to saturation. Note also that, as often observed in this region, the profile of relative humidity displays large fluctuations, with laminated structures between 2000 and $10000 \mathrm{~m}$. They may correspond to traces of dissipated clouds. Finally, a specificity of West Africa is the existence of the African easterly jet, located at about $4000 \mathrm{~m}$. The early-morning low-level jet is also a typical feature. However, this jet is quickly eroded and wind speed decreases substantially within a few hours on this day (at 0900 UTC it is already less than $5 \mathrm{~m} \mathrm{~s}^{-1}$ in the boundary layer, L11 Figure 3).

In agreement with earlier findings from HAPEX-Sahel (Goutorbe et al., 1997), observations point to the existence of large-scale advection in the morning for this case. In the simple framework adopted here, they have to be prescribed. They are loosely based on the ECMWF reanalysis (Agusti-Panareda et al., 2010) together with inferences from observations. Namely, they consist in a cooling $\left(0.3 \mathrm{~K} \mathrm{~h}^{-1}\right.$ maximum) and a moistening $\left(0.3 \mathrm{~g} \mathrm{~kg}^{-1} \mathrm{~h}^{-1}\right.$ maximum $)$ of the low levels in the morning (Figure 6(b) and (c)). This is a simple but physically based approach accounting for the thermodynamic impact of the monsoon flow. In fact, the vertical structure, magnitude and diurnal phasing of these advective processes are fairly consistent with the horizontal advection simulated by the ECMWF analysis over the Sahel prior to the monsoon onset (not shown) and with the results of Peyrille and Lafore (2007) and Gounou (2011).
Surface data and satellite products (Figure 9 in L11) show the existence of mesoscale surface heterogeneities resulting from recent rain events. In particular, a warm anomaly is present where the system initiates. This is in agreement with Taylor et al. (2011), who highlighted a preference for convective initiation over dry/warm surfaces. These surface contrasts may have favoured mesoscale circulations by inducing a lowlevel convergence in the area of initiation. In the simulation, homogeneous surface conditions were chosen for simplicity. However, a large-scale vertical velocity of $1.5 \mathrm{~cm} \mathrm{~s}^{-1}$ from 1200 to 1800 UTC is prescribed (Figure 6(a)). This involves, as an implicit assumption, that the ascent is realized at a scale that is larger than simulated. This is debatable as it certainly leads to a distortion of the actual flow patterns. Nevertheless, it is still valuable to assess its impact on the simulation. Sensitivity tests to this ascent are presented in section 4 .

\subsection{A comprehensive evaluation of the simulation against observations}

In this section, we take advantage of the numerous observations acquired this day in the vicinity of Niamey to evaluate the simulation extensively. Meteorological station data, soundings, aircraft in situ data, radar data, cloud radar and lidar data are used to infer the realism of the simulation (for information on these data see Table I).

The simulation reasonably reproduces the vertical structure of the atmosphere as attested by the comparison to radio soundings and aircraft soundings shown in Figure 7. The domain-mean profiles are compared to different soundings of the atmosphere that are local measurements. Both indicate that the boundary layer grows (about $10 \mathrm{~cm} \mathrm{~s}^{-1}$ from 1000 to 1400 UTC), warms (about $1 \mathrm{~K} \mathrm{~h}^{-1}$ ) and dries (about $-0.5 \mathrm{~g} \mathrm{~kg}^{-1} \mathrm{~h}^{-1}$ ) throughout the day. Note that different boundary layer heights with similar potential temperatures are observed despite the time separation between the aircraft sounding ( $1.5 \mathrm{~h}$ later $)$ and the radio sounding. This suggests the existence of horizontal heterogeneities; the boundary layer sampled by the aircraft possibly started from cooler conditions. Heterogeneities are also revealed by the five meteorological stations located in a radius of $50 \mathrm{~km}$ around Niamey (not shown) and by land surface temperature observed by satellite (Figure 9 of L11). The sounding at 1730 sampled a convective downdraft, as discussed in L11. Thus, in particular, we do not expect that the domain-mean potential temperature displays the strong 
(a)

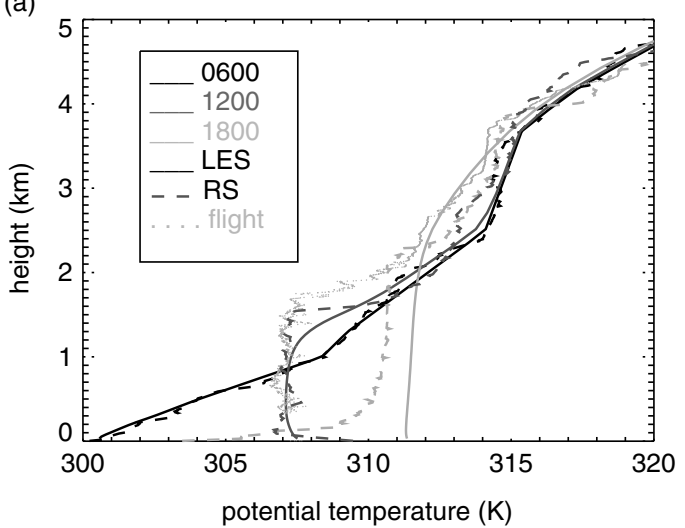

(b)

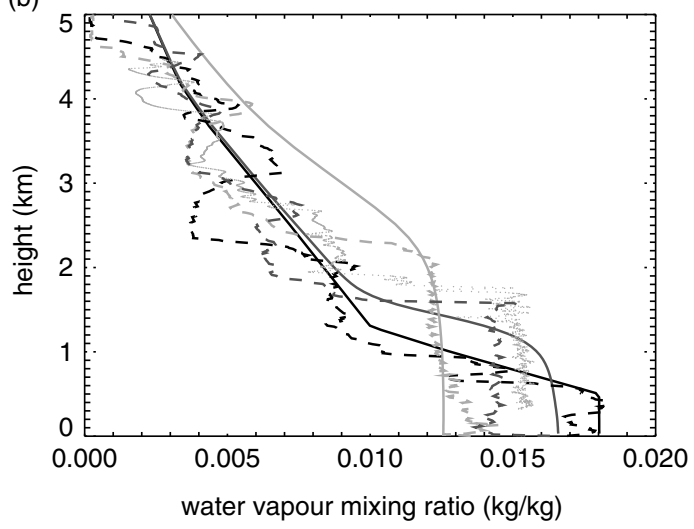

Figure 7. Vertical profiles of (a) potential temperature and (b) water vapour mixing ratio at 0600 (black), 1200 (dark grey) and 1800 (light grey) UTC simulated (plain) and observed by the soundings (dashed) at 0530, 1130 and 1730 and the aircraft (dotted) at 1300 UTC.

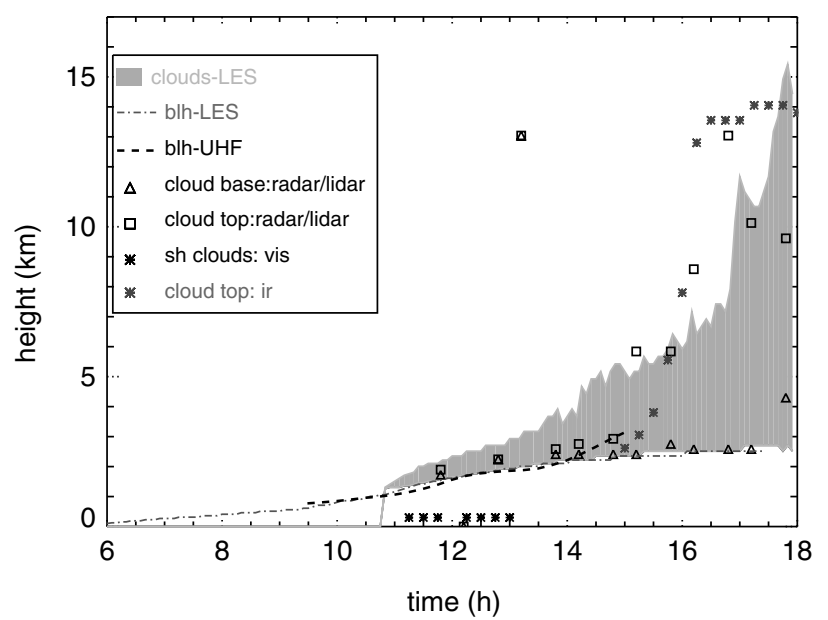

Figure 8. Time evolution of cloud base and cloud top from the simulations (shaded) and from observations (triangles/squares for cloud base/top derived from lidar/radar measurement of the AMF; Black stars indicate time where clouds are detected in the visible MSG satellite images and grey stars delimit the maximum cloud top determined from the infrared MSG satellite images after 1500 UTC) and boundary-layer height derived from the UHF profiles (black dashed line) and from the simulation (grey dash-dotted line).

cooling observed close to the surface, which is the signature of a cold pool. The meteorological station at the AMF allows us to confirm the time evolution of the boundary layer characteristics such as potential temperature and water vapour mixing ratio at $2 \mathrm{~m}$ and wind speed at $10 \mathrm{~m}$ (not shown). As shown in Figure 7, the simulated boundary layer is, however, too moist in the morning and then overestimates the subsequent drying (this issue is discussed in the next section). The boundary layer depth, determined as the level of minimum of the domain-mean buoyancy flux, is compared to observations derived from the UHF profiler in Figure 8. From 0930 to 1400 UTC, there is a good agreement between observations and simulations.

The time evolution of the cloud development in the simulations is compared to the observations from the AMF, where the combination of cloud lidar and cloud radar measurements allows the determination of cloud base and top (Bouniol et al., 2011). In the simulation, cumuli start to form at about 1100 UTC - a bit earlier than observed. The cloud thickness deepens progressively reaching $1000 \mathrm{~m}$ around 1315 UTC in the simulation and $3000 \mathrm{~m}$ around 1500 UTC. In the observations, the cloud depth also reaches
$3000 \mathrm{~m}$ at about 1500 UTC. However, these observed vertical profiles only provide a narrow view of the clouds that develop in the area. To complement those very local observations, cloud tops and occurrences identified by Meteosat Second Generation (MSG) visible and infrared channels on the domain $13.2-13.9^{\circ} \mathrm{N}$ and $1.8-2.7^{\circ} \mathrm{E}$ are also indicated by stars. The dark stars denote the time where the presence of low-level shallow clouds is detected with the visible channel (a pixel is identified as cloudy if there is a significant increase in the reflectance of the pixel in a $15 \mathrm{~min}$ time step), confirming the existence of shallow clouds as soon as 1100 UTC. The grey stars mark the maximum cloud top inferred from infrared image, ${ }^{*}$ confirming initiation of convection at about 1615 UTC. However, the transition from shallow to deep seems more rapid in the observations than the simulations. This will be looked at further in the future.

The simulation reproduces the strong increase in LCL, the decrease in the level of free convection associated with the increase in CAPE up to 1000 UTC and the increase in the level of free convection associated with the decrease of the CAPE afterwards, as well as the decrease in CIN (Figure 3). Even though it is not possible to reach definite conclusions solely based on local data, and despite large variations of these parameters for modest changes of temperature and humidity (as shown by bars indicating the variability), the simulation seems to overestimate the CAPE and to underestimate the level of free convection and the CIN derived from the soundings at midday. In the simulation, convective indexes are derived from the domain-averaged profiles, but the computation of individual column highlights variability of the order of $10 \%$ of the value for CAPE, $50 \%$ for CIN and $100 \mathrm{hPa}$ for LFC (not shown). In addition, the $6 \mathrm{~h}$ time frequency of radiosonde launch does not allow capture of the simulated early-morning increase in CAPE (maximum at 1000 UTC). Interestingly, the observed $2 \mathrm{~m}$ equivalent potential temperature, which is strongly linked to CAPE, displays a very similar morning increase, also followed by a decrease afterwards (Figure 3).

L11 showed the existence of boundary layer organization evolving from morning rolls (their Figure 6(a)) to afternoon cells and then the appearance of deeper isolated convective elements associated with density currents. The simulation

*They are only indicated after 1500 UTC, corresponding to the time when clouds are sufficiently large and high to be distinguished from the surface. 

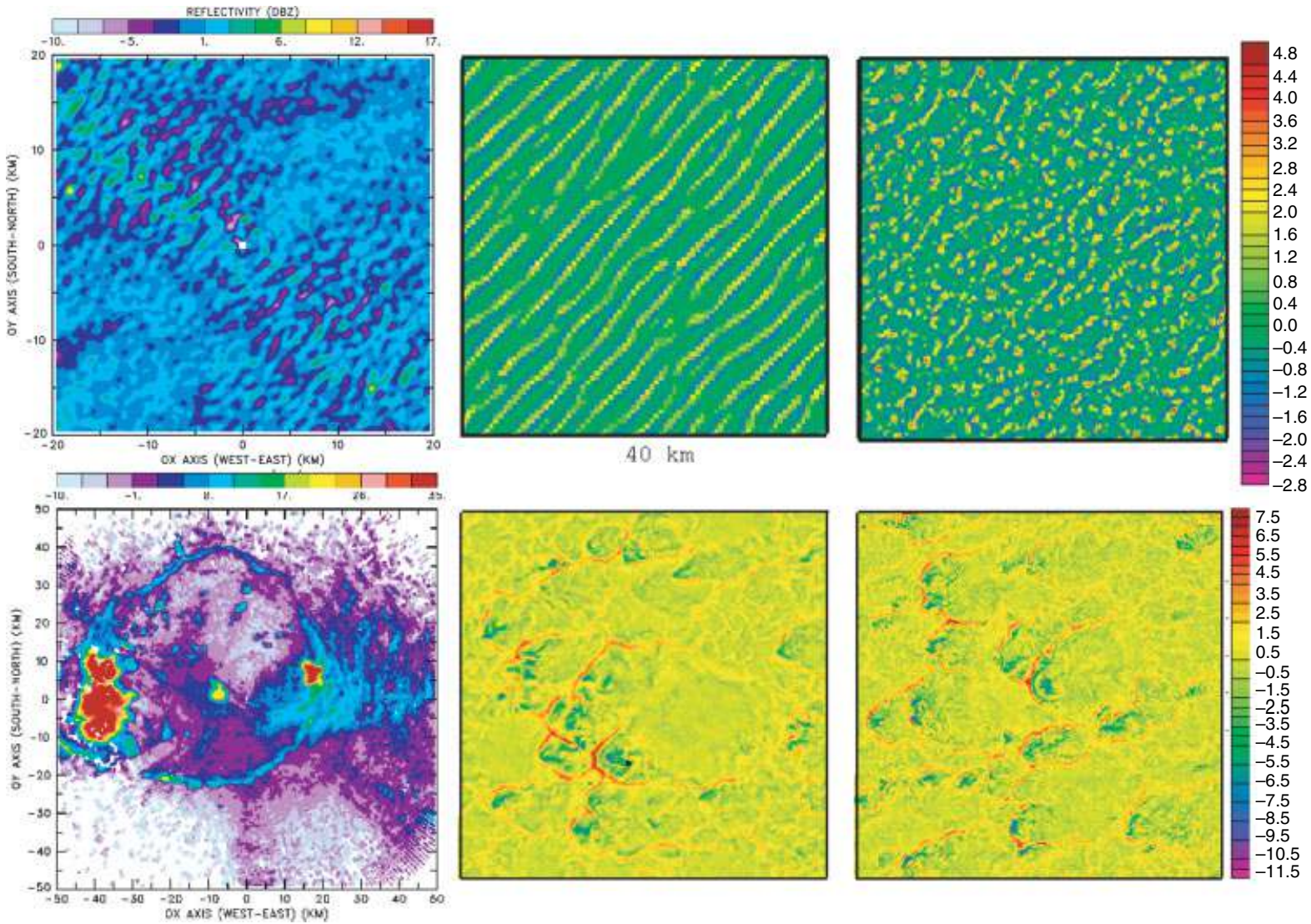

Figure 9. Horizontal cross-section at $600 \mathrm{~m}$ above ground level at 1000 (upper panels) and 1800 (lower panels) UTC of reflectivity observed by MIT radar (left: the data corresponds to horizontal resolution of $200 \mathrm{~m}$ ) and of the vertical velocity in the REF (centre: horizontal resolution of $500 \mathrm{~m}$ ) and HRND (right: horizontal resolution of $200 \mathrm{~m}$ ) simulations. The black dot in the centre lower panel indicates the position of the profiles of Figure 11. Bottom left figure is reproduced from L11.

also presents an organization in the boundary layer (Figure 9, upper panels). At 1000 UTC, the observations indicate band-like structures, whereas the REF simulation using a $500 \mathrm{~m}$ horizontal grid still indicates true rolls with orientation aligned with the boundary layer mean wind. On the other hand, the simulation predicts the first intense cells (associated with precipitation) at about 1600 UTC, consistent with radar observations (not shown) as well as the organization of convection into larger structures (Figure 9, lower panels) and the spreading of circular large cold pools characterized by slow descending motion.

The LES is also found to correctly represent the main characteristics of the turbulence associated with a convective boundary layer (Figure 10), with a positively skewed distribution of vertical velocity and potential temperature, and here a negatively skewed distribution of the water vapour mixing ratio (see Couvreux et al., 2007: Canut et al., 2010). Nevertheless, there are some differences. The main differences concern the vertical velocity and appear to be at least partly related to contrasts between the surfaces over which the aircraft flew and the area where the AMF was installed. The legs were flown over Banizoumbou, where the maximum recorded surface heat flux was only $200 \mathrm{~W} \mathrm{~m} \mathrm{~m}^{-2}$. In addition, a close inspection of the legs indicates heterogeneities of scale that have not been taken into account in the simulation, in particular for the water vapour mixing ratio.

Towards the end of the simulation, a few density currents, driven by rain evaporation, are spreading in the low levels (Figure 9). As previously discussed, a density current was also sampled by the sounding launched at 1730 UTC. It is cooler (by $8 \mathrm{~K}$ ) but also moister ${ }^{\dagger}$ (by almost $2 \mathrm{~g} \mathrm{~kg}^{-1}$ ) than the boundary layer it is intruding into (Figure 11(a)). This current is about $1.5 \mathrm{~km}$ thick. The simulation reproduces similar characteristics as illustrated in Figure 11(b), showing vertical profiles at one particular point located in Figure 9. Nevertheless, in the simulation, some density currents are also found to be drier.

Deep convection dramatically impacts BL structures and this is reflected in distributions as shown in Figure 12. The vertical velocity distribution changes from a positively skewed distribution until 1600 UTC, to an almost symmetric distribution, and the potential temperature distribution shifts from a positively skewed to a negatively skewed distribution. The modifications of the water vapour mixing ratio and the equivalent potential temperature (not shown) are much smaller in contrast to Tompkins (2001), even though the negative skewness of these distributions increased from 1600 to 1800 UTC. This highlights the role of cold pools in the modification of boundary layer structures by deep convection.

In summary, the high-resolution simulation is able to represent the growing boundary layer with associated turbulent structures, the transition to shallow clouds and the initiation of deep convection. The main discrepancy is the too moist boundary layer in the morning. Note that

\footnotetext{
Observations show that density currents can often be relatively moist in the Sahel prior to the monsoon onset, especially when they occur within a boundary layer that experienced high daytime drying.
} 
(a)

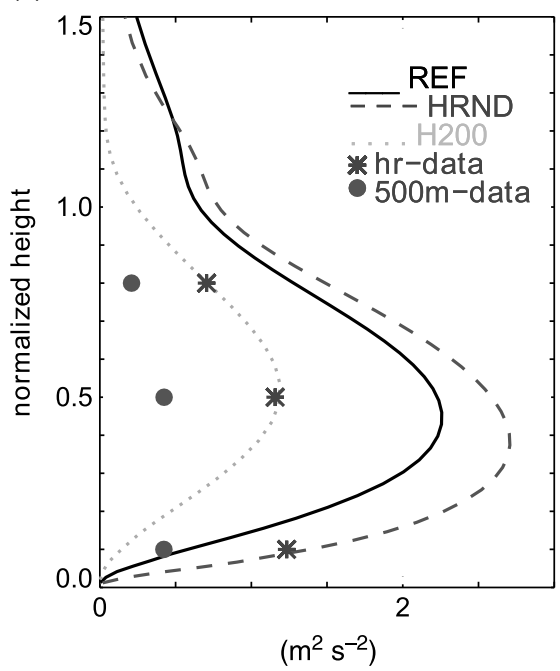

(d)

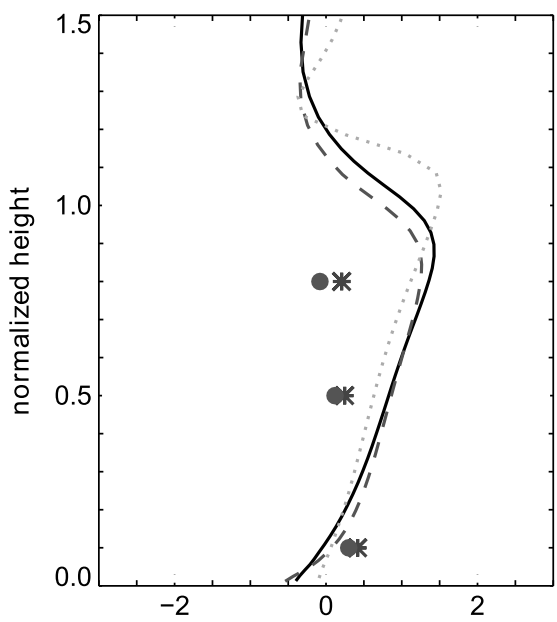

(b)

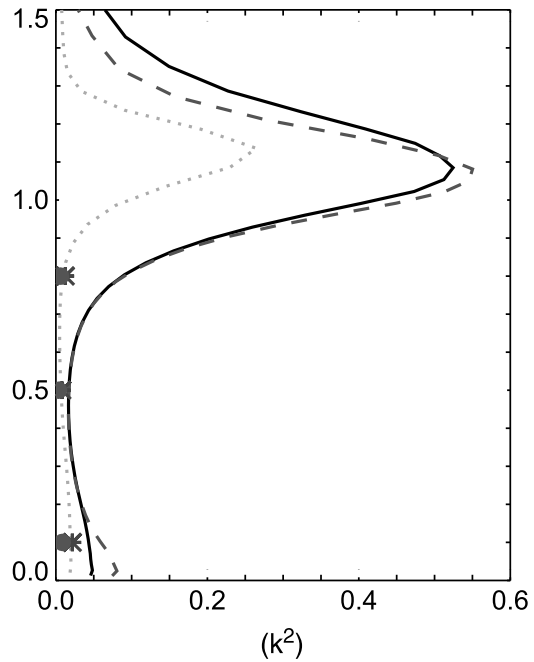

(e)

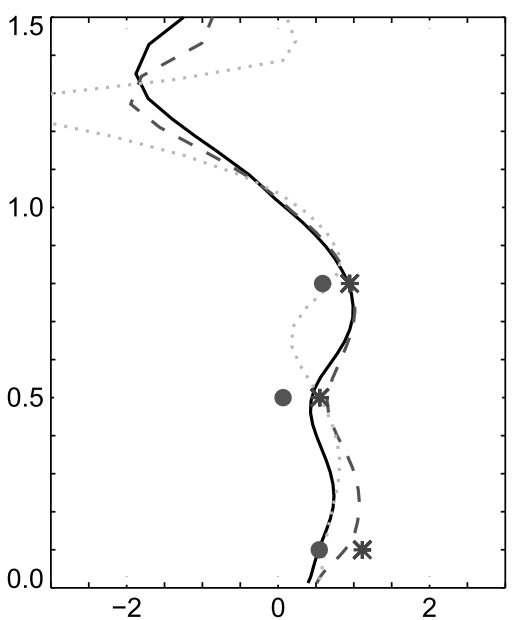

(c)

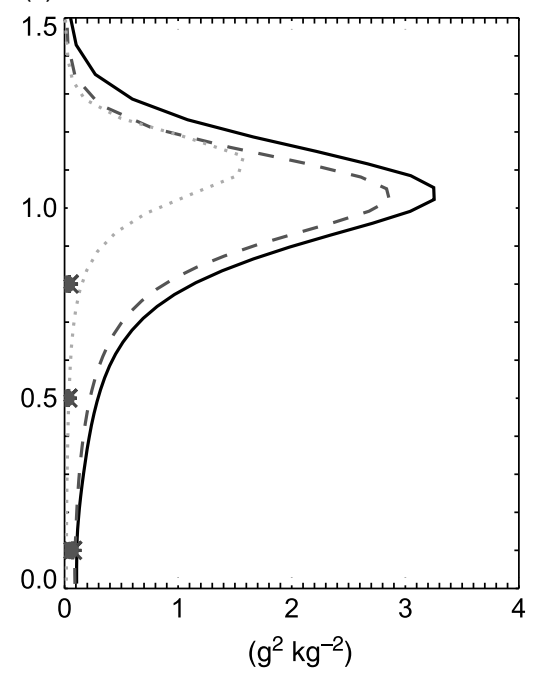

(f)

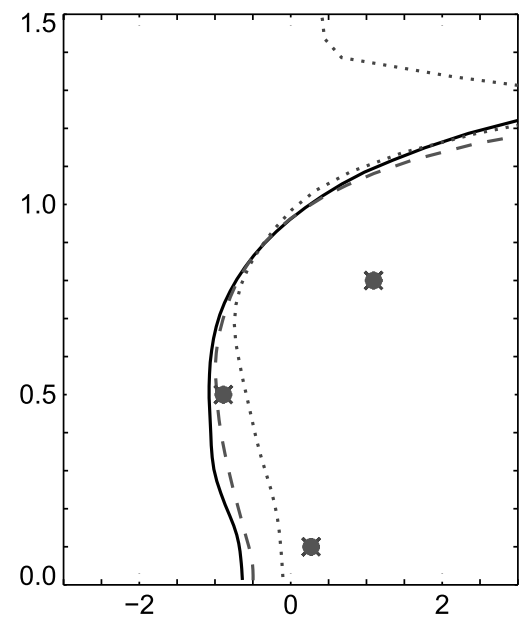

Figure 10. Vertical profile of variance (top panels) and skewness (bottom panels) of vertical velocity (left), potential temperature (centre) and water vapour mixing ratio (right) in the simulations at 1200 UTC (REF in black, HRND in dashed dark grey and H200 in light grey) and in aircraft observations (in symbols) as a function of height normalized by the boundary layer.

Numerical Weather Prediction models were not able to predict initiation of convection around Niamey on this day.

\subsection{Importance of resolution and domain size}

To evaluate the sensitivity to geometric configuration, three additional simulations have been performed: HRSD with a resolution of $200 \mathrm{~m}$ over a small domain of $20 \mathrm{~km} \times 20 \mathrm{~km}$, NRBD with the same resolution as the reference but with a larger domain of $200 \mathrm{~km} \times 200 \mathrm{~km}$, and HRND with a high resolution of $200 \mathrm{~m}$ over the reference domain of $100 \mathrm{~km} \times$ $100 \mathrm{~km}$.

A finer horizontal resolution of $200 \mathrm{~m}$ (HRSD or HRND) instead of $500 \mathrm{~m}$ (REF or NRBD) leads to a slightly different organization of the boundary layer: structures evolve into cells $0.5-1 \mathrm{~h}$ earlier (Figure 9); shallow cumulus clouds also develop about half an hour earlier (Table III) and the total cloud fraction is slightly higher (not shown). It is satisfactory to verify that higher-resolution simulations, which allow better resolution of the structures associated with convection, also provide a closer match to the observed band-like structures (Figure 9, upper panel). Nevertheless, the main characteristics of HRND are reproduced by REF in terms of turbulence (Figure 10; also, distributions obtained with HRND are very similar to Figure 12) and cloud development (Figure 13). Thus the $500 \mathrm{~m}$ grid appears sufficient to reproduce the essential processes for convective initiation, in agreement with G06.

By contrast, with a smaller domain (HRSD), the horizontal and vertical extensions of the clouds are more limited (Table III and Figure 13), indicating too small a domain prevents deep cloud growth. Clouds are also far fewer within this 25 times smaller domain and cloud individual life cycles lead to marked fluctuations in the domain-mean liquid water path (LWP) and rainwater path (RWP). At the end of the simulation, the REF domain itself is possibly becoming too small, as the cyclic conditions seem to force larger clouds compared to HRND (Figure 9), whereas NRBD reproduces a similar cloud size to HRND (not shown).

In conclusion, a large domain (at least $100 \mathrm{~km}$ wide) is needed to be able to simulate the initiation of deep convection. Similar results are obtained in REF and HRND except for the better-resolved boundary-layer structures with high resolution. Thus resolution does not appear as a major issue with this model as the main features are captured with the $500 \mathrm{~m}$ horizontal grid of REF. 
(a)

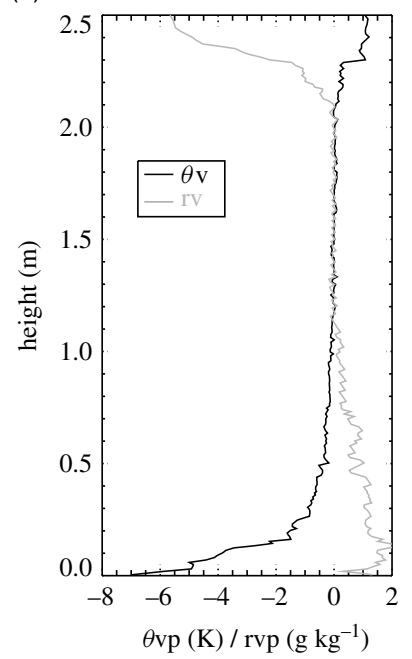

(b)

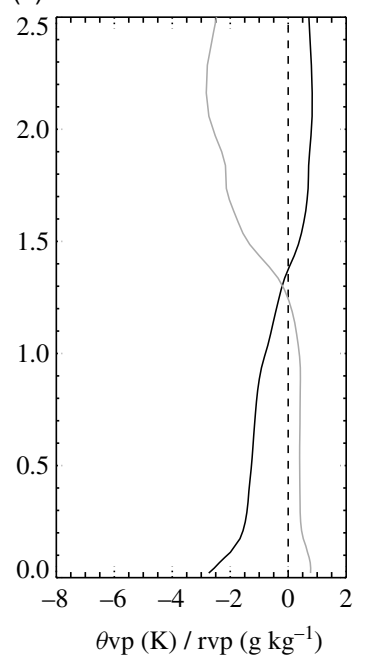

Figure 11. Vertical profiles of virtual potential temperature anomaly (black) and water vapour mixing ratio anomaly (light grey) observed by the 1730 UTC sounding (a) and simulated by REF at 1800 UTC at one location (indicated by the black dot in Figure 9) in REF simulation (b). The anomaly for the sounding is computed relative to the mean value between 1000 and $2000 \mathrm{~m}$.

\subsection{Heat source and moisture sink}

Physical processes strongly shape the thermodynamic budgets of this daytime convection, as shown in Figure 14 for heat and moisture for the three phases: dry convection (from the early morning until 1110 UTC), shallow convection (from 1110 to 1600 UTC) and deep convection (from 1600 UTC to the end of the simulation). In the first phase, thermals contribute to significantly mix the levels below $2000 \mathrm{~m}$, moistening and cooling the levels above $800 \mathrm{~m}$. After 1110 UTC, the microphysics processes play a significant role (mainly condensation/evaporation of cloud droplets up to 1600 UTC and then also precipitation). During this phase, the boundary layer is warmed $\left(0.8 \mathrm{~K} \mathrm{~h}^{-1}\right)$ and dried $\left(-0.7 \mathrm{~g} \mathrm{~kg}^{-1} \mathrm{~h}^{-1}\right)$, whereas the $2000-5000 \mathrm{~m}$ layer is cooled $\left(-0.3 \mathrm{~K} \mathrm{~h}^{-1}\right)$ and moistened $\left(0.7 \mathrm{~g} \mathrm{~kg}^{-1} \mathrm{~h}^{-1}\right)$. The cooling of the levels between 2000 and $4000 \mathrm{~m}$ is about twice as large as the apparent heat source and moisture sink associated with shallow cumulus convection over the tropical ocean observed by Siebesma and Cuijpers (1995). This underlines the more significant role of continental versus oceanic cumulus in the transport of moisture to the levels $1500-4000 \mathrm{~m}$. The shape of the transfer of heat and moisture during the deep convective phase is typical (Guichard et al., 1997, STG2 phase) with a cooling close to the surface and a warming above, coupled to a drying below $2000 \mathrm{~m}$ and a moistening up to $8000 \mathrm{~m}$. Therefore, those small convective systems contribute significantly to the moistening (about $0.5 \mathrm{~g} \mathrm{~kg}^{-1} \mathrm{~h}^{-1}$ ) of the levels above $4000 \mathrm{~m}$.

\section{The transition from shallow to deep convection}

For this case study, the transition from shallow to deep convection (here the time of initiation of deep convection is determined by the moment at which the maximal cloud vertical extension reaches $8000 \mathrm{~m}$ ) is about $6 \mathrm{~h}$ duration in REF (about $5 \mathrm{~h}$ in observations; cf. Figure 8). This is longer than in the wetTropic case, which is about $3 \mathrm{~h}$ (KR06), and in the midLat case, which is about $4 \mathrm{~h}$ (G04). In

the following, we focus on the sensitivity of the transition to the initial profiles, the boundary conditions and the rain processes. These sensitivity tests highlight the key conditions that lead to initiation of deep convection. Finally, different criteria used in the literature to determine the timing of the transition are tested.

\subsection{Sensitivity of transition to initial profiles}

To evaluate the sensitivity to the initial profiles, modifications (see Table II for details of the sensitivity tests) are applied independently on the moisture (PLOW, LLOW, PMID, LMID, PHIG, LHIG), potential temperature (PSTA, LSTA) and wind speed (NoAEJ, see also Figure 5) initial profiles. Note that all changes are in the range of observed changes recorded at Niamey.

The simulation is sensitive to the initial profile of water vapour mixing ratio as in Crook (1996), even though here we do not focus on thermodynamical variable drop-off between the surface and the boundary layer but more on boundary layer characteristics. As expected, moister initial profiles lead to earlier initiation of deep convection, as shown in Figure 15 and Table III, whatever the levels where the water vapour mixing ratio is increased (with a slightly lesser impact for the upper levels). When the low levels are moister, there is also an earlier formation of shallow clouds. Note that the time of transition from shallow to deep is only significantly reduced for moister conditions in the mid levels (PMID, Table III). As shown previously, the REF simulation is too moist in the boundary layer. Nevertheless, decreasing the initial moisture profile leads to even later transition to deep convection.

The simulation with a lower stability (LSTA) leads to an earlier formation of shallow cumulus, similarly to Zhu and Albrecht (2003) and to an earlier initiation of deep convection. In addition, this simulation also has a larger total cloud fraction ( 0.1 more than REF, which has a maximum total cloud fraction of 0.15 ) and greater precipitation (Figure 15), and its transition from shallow to deep is shorter. Thus relatively minor fluctuations of the initial profiles of water vapour mixing ratio and potential temperature both have a large impact on the timing and basic features of this daytime convective sequence and its sensitivities are in broad agreement with Zhang and Klein (2010). In conclusion, the relatively moist and weakly stable low levels are important for the initiation of convection.

The suppression of the African easterly jet (NoAEJ) located at about $4000 \mathrm{~m}$ leads to a greater cloud depth, LWP and RWP during the transition phase from 1400 to 1600 UTC (Figure 15). However, afterwards, deep convection develops less, is organized into smaller cells, and the total cloud fraction is smaller (not shown). This jet thus appears first as a favourable factor and then an inhibiting factor, which distorts and dilutes growing shallow clouds. This points to a somewhat complex role of the wind field depending on the considered phase. While most current parametrizations of convection ignore the wind field, our results emphasize the need to further explore the significance of this environmental factor.

\subsection{Sensitivity of the transition to boundary conditions:} large-scale advections and surface fluxes

Here we evaluate the sensitivity to boundary conditions, both to the energy input through surface fluxes and to large-scale 
(a)

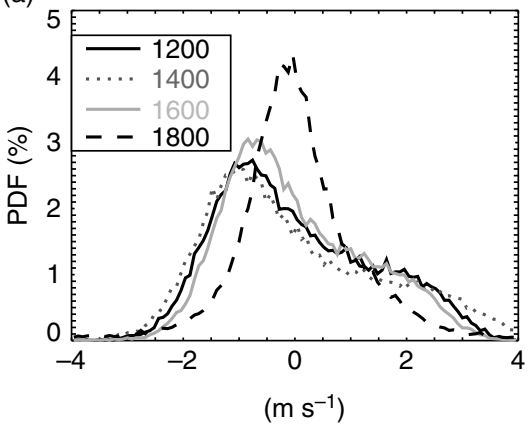

(b)

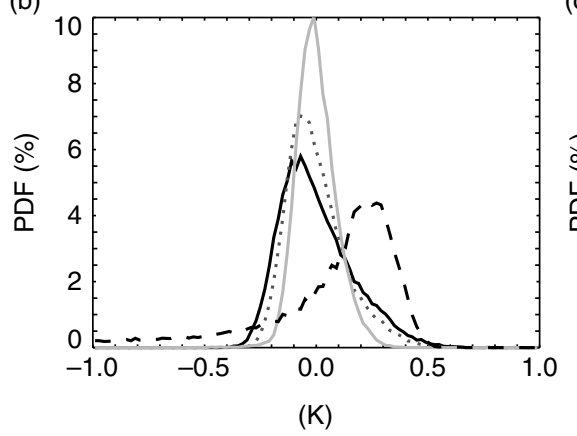

(c)

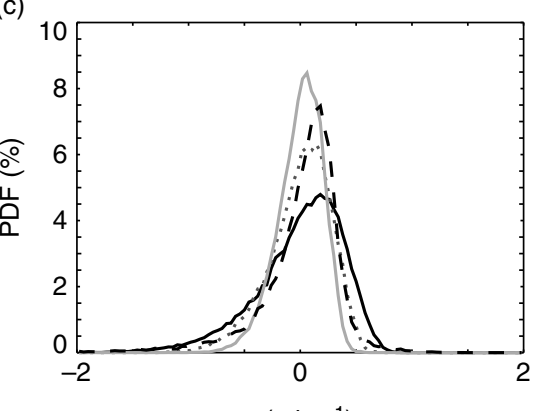

Figure 12. Distribution of (a) vertical velocity, (b) potential temperature anomaly and (c) total water mixing ratio anomaly at low levels at 0.25 zi at 1200 (black), 1400 (dotted dark grey), 1600 (light grey) and 1800 (dashed) UTC.

(a)

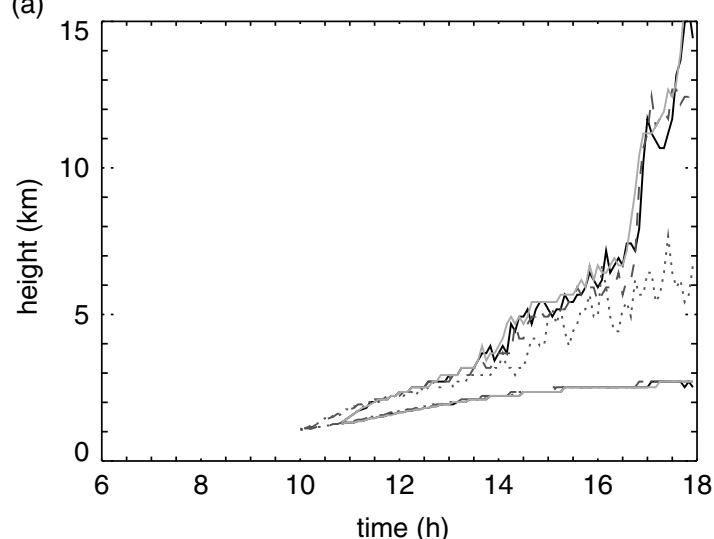

(b)

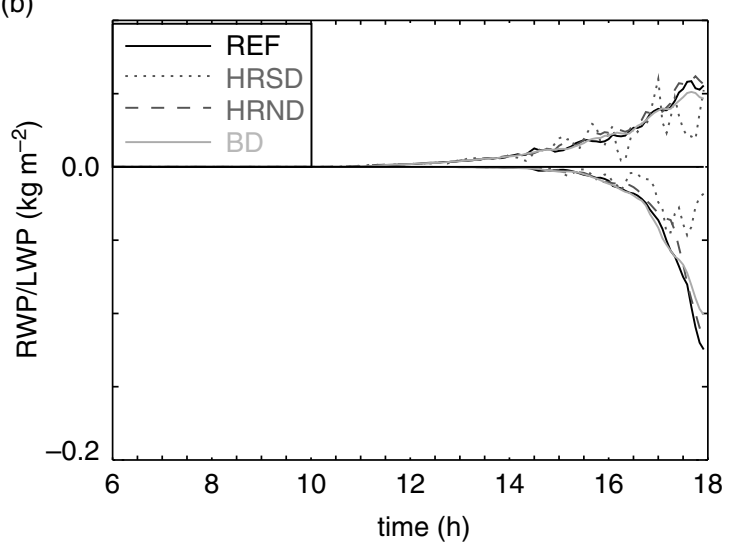

Figure 13. Time series of (a) minimum cloud base and maximum cloud top and (b) LWP and RWP (RWP is multiplied by -1 for clarity) in the reference simulation (REF, black), the small domain simulation (HRSD, dotted dark grey), high-resolution simulation (HRND, dashed dark grey) and large domain simulation (LRBD, light grey). Note that the cloud base for all simulations is the same.

(a)

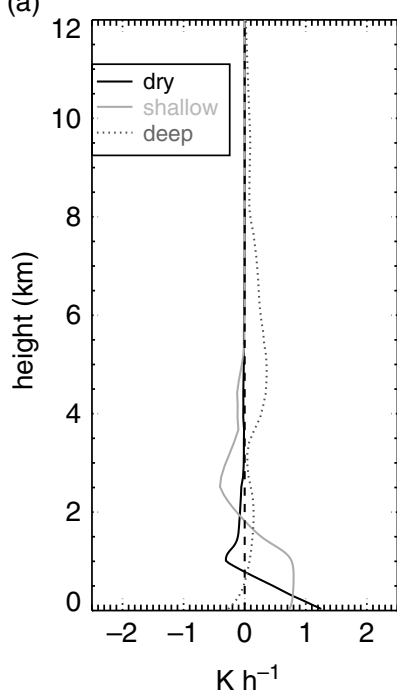

(b)

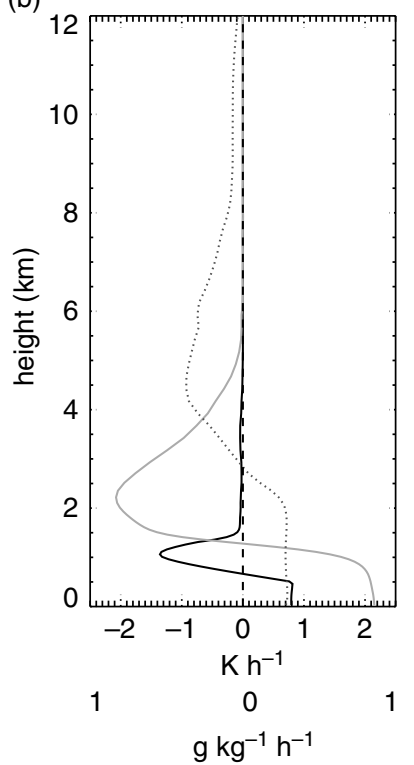

Figure 14. (a) Mean apparent heat source (Q1) and (b) moisture sink (Q2) for the dry convection phase (before 1110 UTC, black), shallow convection phase (between 1110 and 1600 UTC, light grey) and deep convection phase (after 1600 UTC, dotted dark grey).

horizontal and vertical advection. Concerning the surface fluxes, a simulation (H200) with a reduced sensible heat flux reaching only $200 \mathrm{~W} \mathrm{~m}^{-2}$ instead of $350 \mathrm{~W} \mathrm{~m}^{-2}$ and a simulation (BO1) with a Bowen ratio of 1 instead of 10

(corresponding to both heat fluxes reaching $200 \mathrm{~W} \mathrm{~m}^{-2}$ ) were performed. Note that a maximum of $200 \mathrm{~W} \mathrm{~m} \mathrm{~m}^{-2}$ corresponds to what has been observed at Banizoumbou, where the aircraft flew. A series of simulations with different large-scale vertical velocities (still imposed between 1200 and 1800 UTC) of respectively $0,1,2$ and $3 \mathrm{~cm} \mathrm{~s}^{-1}$ (W0, $\mathrm{W} 1, \mathrm{~W} 2, \mathrm{~W} 3$ ) and a simulation with no horizontal advection (Noadv) were then performed.

A lower sensible heat flux ( $\mathrm{H} 200$ and BO1) leads to a cooler (respectively 1.5 to $2.5 \mathrm{~K}$ ), smaller and moister (respectively 1.5 to $3 \mathrm{~g} \mathrm{~kg}^{-1}$ ) boundary layer than REF (not shown). This is evidenced by a lower cloud base (respectively 600 and $900 \mathrm{~m}$ lower than REF, Figure 16). Nevertheless, apart from the delay and a smaller cloud base, evolution of the cumulus depth is very similar to REF, as in Zhu and Albrecht (2003). The boundary layer is organized into rolls for a longer period than in REF, and this is consistent with changes in BLh $/ L_{\mathrm{MO}}$, with $L_{\mathrm{MO}}$ being the Monin-Obukhov length (e.g. Weckwerth et al., 1999). However, importantly, in those simulations deep convection never occurs and the clouds remain shallow throughout the day, limiting the transfer of moisture to the levels below $3000 \mathrm{~m}$. There is very little precipitation and almost no formation of ice or graupel. For such sensible heat flux, increasing the latent heat flux (BO1 compared to H200) is not sufficient for deep convection to initiate. For those semi-arid conditions, the existence of large sensible heat flux appears as a necessary condition for deep convective initiation.

Similarly, the onset of deep convection is very sensitive to the afternoon large-scale ascent $\left(w_{\mathrm{LS}}\right)$. For values of $w_{\mathrm{LS}}$ 
Table II. Characteristics of the numerical experiments: only the differences relative to REF are indicated.

\begin{tabular}{|c|c|c|c|c|c|c|c|c|c|c|c|c|}
\hline & $\begin{array}{l}\text { horizont } \\
\text { resolutio }\end{array}$ & $\begin{array}{l}\text { l domain } \\
\text { length }\end{array}$ & $\begin{array}{l}H \\
\left(\mathrm{~W} \mathrm{~m}^{-2}\right)\end{array}$ & $\begin{array}{l}\mathrm{LE} \\
\left(\mathrm{W} \mathrm{m}^{-2}\right)\end{array}$ & $\begin{array}{l}q_{\mathrm{LOW}} \\
\left(\mathrm{g} \mathrm{kg}^{-1}\right)\end{array}$ & $\begin{array}{l}q_{\mathrm{MID}} \\
\left(\mathrm{g} \mathrm{kg}^{-1}\right)\end{array}$ & $\begin{array}{l}q_{\mathrm{HIG}} \\
\left(\mathrm{g} \mathrm{kg}^{-1}\right)\end{array}$ & $\begin{array}{l}\Gamma_{500-4200} \\
\left(\mathrm{Kkm}^{-1}\right)\end{array}$ & $\begin{array}{l}\Gamma_{500-1300} \\
\left(\mathrm{Kkm}^{-1}\right)\end{array}$ & & $\begin{array}{l}\text { WLS } \\
\left(\mathrm{cms}^{-1}\right)\end{array}$ & Rain \\
\hline & $\begin{array}{l}\Delta x= \\
\Delta y(\mathrm{~m})\end{array}$ & $\begin{array}{l}L x= \\
L y(\mathrm{~km})\end{array}$ & & & {$[0-750 \mathrm{~m}]$} & {$[750-300$} & ]$[3-5 \mathrm{~km}]$ & & & & & \\
\hline REF & 500 & 100 & $H_{\mathrm{o}}$ & $\mathrm{LE}_{\mathrm{o}}$ & $q_{\mathrm{o}}$ & $q_{\mathrm{o}}$ & $q_{\mathrm{o}}$ & 3.6 & 6.5 & Yes & 1.5 & Yes \\
\hline HRSD & 200 & 20 & - & - & - & - & - & - & - & - & - & - \\
\hline HRND & 200 & - & - & - & - & - & - & - & - & - & - & - \\
\hline NRBD & - & 200 & - & - & - & - & - & - & - & - & - & - \\
\hline PLOW & - & - & - & - & $q_{\mathrm{o}}+0.5$ & - & - & - & - & - & - & - \\
\hline LLOW & - & - & - & - & $q_{\mathrm{o}}-0.5$ & - & - & - & - & - & - & - \\
\hline PMID & - & - & - & - & - & $q_{\mathrm{o}}+0.5$ & - & - & - & - & - & - \\
\hline LMID & - & - & - & - & - & $q_{\mathrm{o}}-0.5$ & - & - & - & - & - & - \\
\hline PHIG & - & - & - & - & - & - & $\begin{array}{l}q_{\mathrm{o}}+ \\
0.5\end{array}$ & - & - & - & - & - \\
\hline LHIG & - & - & - & - & - & - & $\begin{array}{l}\mathrm{q}_{\mathrm{o}}- \\
0.5\end{array}$ & - & - & - & - & - \\
\hline PSTA & - & - & - & - & - & - & - & 3.7 & 7.4 & - & - & - \\
\hline LSTA & - & - & - & - & - & - & - & 3.2 & 5.5 & - & - & - \\
\hline NoAEJ & - & - & - & - & - & - & - & - & - & No & - & - \\
\hline $\mathrm{H} 200$ & - & - & $H_{\mathrm{o}} / 1.75$ & - & - & - & - & - & - & - & - & - \\
\hline Bo1 & - & - & $H_{\mathrm{o}} / 1.75$ & $H_{\mathrm{o}} / 1.75$ & - & - & - & - & - & - & - & - \\
\hline Wo & - & - & - & - & - & - & - & - & - & - & 0 & - \\
\hline W1 & - & - & - & - & - & - & - & - & - & - & 1 & - \\
\hline W2 & - & - & - & - & - & - & - & - & - & - & 2 & - \\
\hline W3 & - & - & - & - & - & - & - & - & - & - & 3 & - \\
\hline NoRaisn & & - & - & - & - & - & - & - & - & - & - & No \\
\hline
\end{tabular}

Table III. Time of shallow convection initiation (determined by non-null integrated liquid water content), time of deep convection initiation (determined by cloud depth reaching $8 \mathrm{~km}$ ), horizontal/vertical shallow cumulus size, horizontal/vertical deep cloud size, $\operatorname{maximum}\left(\mathrm{mm} \mathrm{d}^{-1}\right)$ and cumulated $(\mathrm{mm})$ amount of surface precipitation for the different simulations (refer to Table II for name of simulations).

\begin{tabular}{lllccc}
\hline Simulation & $\begin{array}{l}\text { Time of shallow } \\
\text { initiation (UTC) }\end{array}$ & $\begin{array}{l}\text { Time of deep } \\
\text { initiation (UTC) }\end{array}$ & $\begin{array}{c}\text { Shallow cumulus vertical// } \\
\text { horizontal size at } \\
\text { at } 1200 \text { UTC }(\mathrm{m})\end{array}$ & $\begin{array}{c}\text { Deep cloud vertical/ } \\
\text { horizontal size at } \\
\text { at } 1800 \text { UTC }(\mathrm{m})\end{array}$ & $\begin{array}{c}\text { max./cumul. of } \\
\text { precipitation } \\
\left(\mathrm{mm} \mathrm{d} \mathrm{d}^{-1} / \mathrm{mm}\right)\end{array}$ \\
\hline REF & 1110 & 1700 & $750 / 1500$ & $14000 / 12500$ & $5.29 / 0.0698$ \\
HRSD & 1040 & Undef. & $600 / 850$ & $0.36 / 0.0068$ \\
HRND & 1045 & 1700 & $850 / 1000$ & $11150 / 16000$ & $3.27 / 0.0473$ \\
NRBD & 1110 & 1550 & $950 / 1250$ & $14500 / 12000$ & $3.28 / 0.0652$ \\
W0 & 1120 & Undef. & $600 / 1350$ & $0 / 0$ \\
W1 & 1115 & 1855 & $750 / 1450$ & $5900 / 4500$ & $0.07 / 0.0007$ \\
W2 & 1110 & 1555 & $900 / 1500$ & $13500 / 17750$ & $5.50 / 0.268$ \\
W3 & 1105 & 1440 & $1100 / 1500$ & $14100 / 20000$ & $11.06 / 0.722$ \\
Noadv & 1140 & 1625 & $750 / 1400$ & $11200 / 10900$ & $3.04 / 0.0468$ \\
H200 & 1235 & Undef. & - & - & Traces \\
Bo1 & 1210 & Undef. & - & - & Traces \\
PSTA & 1140 & 1825 & $550 / 1450$ & $4900 / 4400$ & $0.03 / 0.0006$ \\
LSTA & 1025 & 1525 & $1250 / 1650$ & $13400 / 22000$ & $12.20 / 0.6174$ \\
NoAEJ & 1115 & 1805 & $750 / 1400$ & $7650 / 6000$ & $0.44 / 0.0125$ \\
PLOW & 1100 & 1610 & $750 / 1400$ & $13650 / 19000$ & $6.79 / 0.1910$ \\
LLOW & 1125 & 1730 & $750 / 1400$ & $9400 / 7700$ & $1.46 / 0.0200$ \\
PMID & 1110 & 1540 & $1000 / 1500$ & $15050 / 19700$ & $6.75 / 0.2065$ \\
LMID & 1110 & 1805 & $750 / 1500$ & $6200 / 6200$ & $0.83 / 0.0079$ \\
PHIG & 1110 & 1620 & $750 / 1500$ & $12900 / 13750$ & $5.36 / 0.1066$ \\
LHIG & 1110 & 1705 & $750 / 1500$ & $12400 / 10500$ & $2.58 / 0.0403$ \\
NORAIN & 1110 & 1655 & $750 / 1500$ & $12450 / 16500$ & 0 \\
\hline
\end{tabular}


(a)

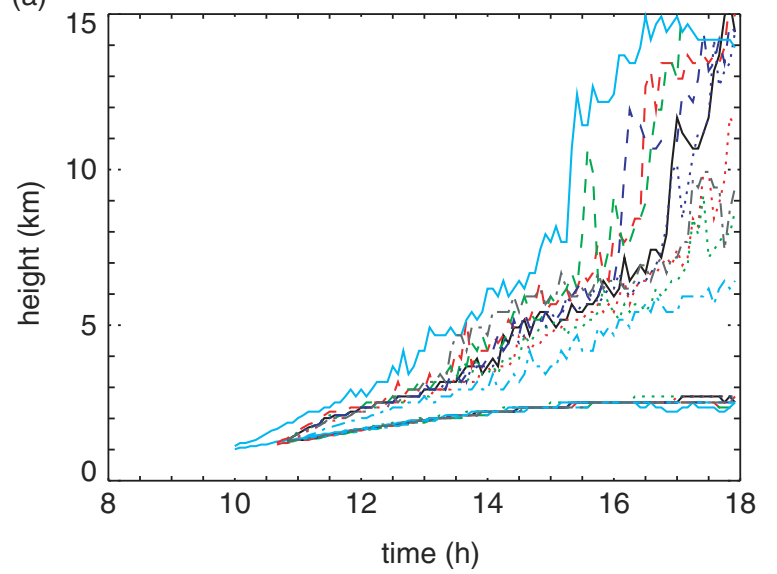

(b)

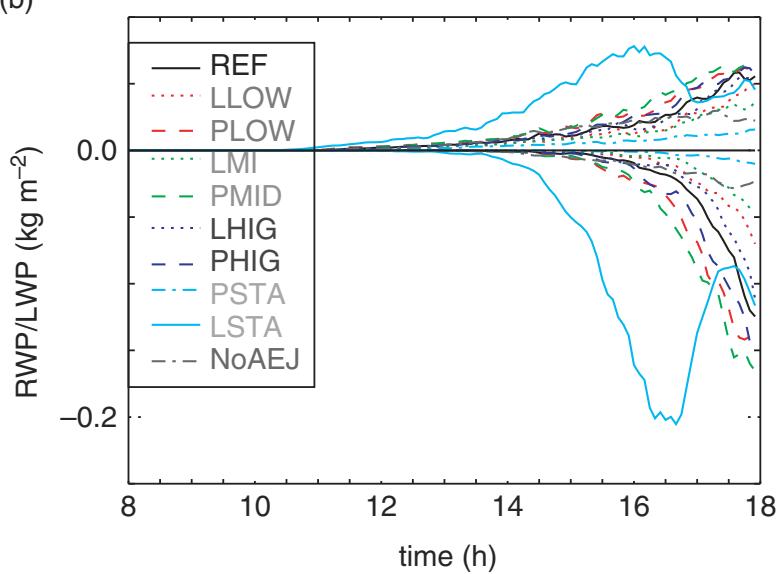

Figure 15. Same as Figure 10 but for the reference simulation (REF, black), and the sensitivity tests to initial conditions (refer to text and Table II for acronyms). Note that the cloud base for all simulations is the same.

(a)

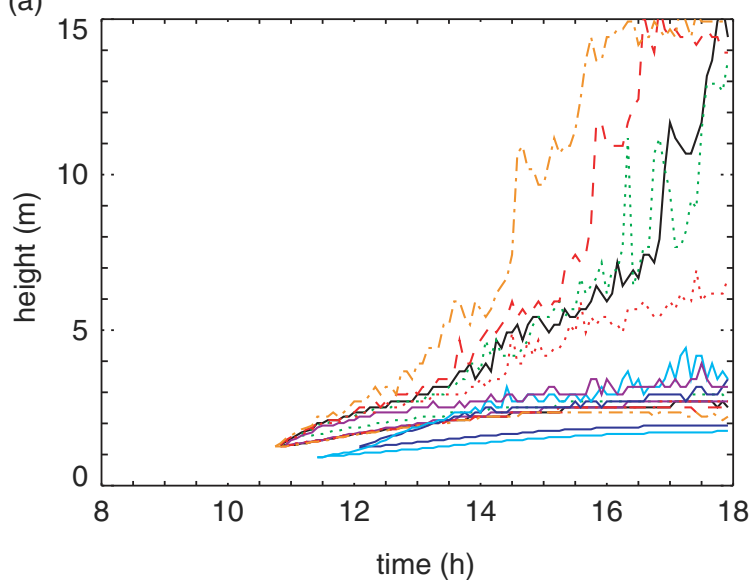

(b)

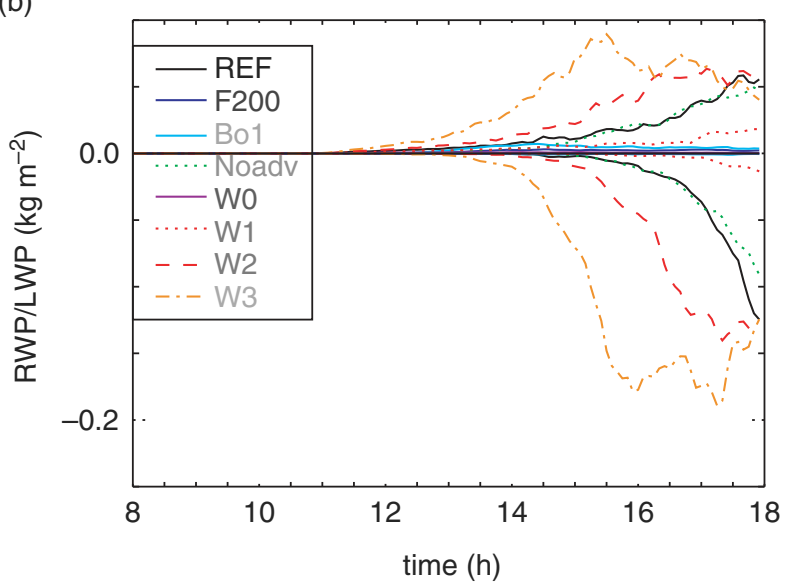

Figure 16. Same as Figure 10 but for the reference simulation (REF, black) and the sensitivity tests to boundary conditions (refer to text and Table II for acronyms).

lower than $1.5 \mathrm{~cm} \mathrm{~s}^{-1}$ deep convection does not initiate (in simulations $\mathrm{W} 0$ and $\mathrm{W} 1$, cloud depth remains below 1000 and $6000 \mathrm{~m}$ respectively; Figure 16 and Table III). With increasing $w_{\mathrm{LS}}$ above $1.5 \mathrm{~cm} \mathrm{~s}^{-1}$, deep convection initiation occurs earlier and the duration of the transition from shallow to deep convection is reduced. However, the evolution of the characteristics of deep convection (maximum cloud height, LWP, RWP, etc.) is very similar after initiation. In this case, a sufficient large-scale vertical velocity is needed in order to initiate deep convection. Such vertical velocity can be due to mesoscale circulation induced by the mesoscale surface property heterogeneities evidenced by observations for this day.

The simulation without horizontal advection leads to a warmer and drier boundary layer. Slightly smaller clouds form and therefore less rain and ice are formed at the end of the simulation. Note also that the time when the maximum cloud depth reaches $5000 \mathrm{~m}$ is similar in Noadv and REF simulations, but without advection the simulation predicts characteristics of deep convection evolving more slowly (cloud depth, LWP, precipitation, etc.). Overall, the simulation is not very sensitive to horizontal advection. Note, nevertheless, that in this simulation the moist bias is partly corrected.

\subsection{Sensitivity of the transition to the rain processes}

A number of studies underline the significance of rain processes taking place within convective systems and, more specifically here, KR06, Piriou et al. (2007) and Rio et al. (2009) addressed their importance in the context of transition from shallow to deep convection. Here, the simulation NORAIN is intended to examine the effects of this component on cloud dynamics by turning off part of the cloud microphysics parametrization: only the warm water saturation adjustment is permitted. In practice, the cloud water cannot be converted into other water substances: in particular, no rain is allowed. Thus evaporatively driven downdrafts are not present.

In the present case, however, the time evolution of the cloud depth is similar in NORAIN and in REF (Figure 17(a)). The LWP is larger, with differences as large as $0.4 \mathrm{~kg} \mathrm{~m}^{-2}$, although this increase in liquid water content does not fully compensate for the precipitation present and other hydrometeors in REF (Figure 17(b)). After deep convection has initiated, the size of the boundary layer structures is much smaller than in REF (Figure 18) as no cold pool forms, in agreement with KR06. The averaged potential temperature profile differs from REF near the ground at the end of the simulation as, when no rain forms, no stratification of the boundary layer due to the induced cooling occurs. Therefore, 
(a)

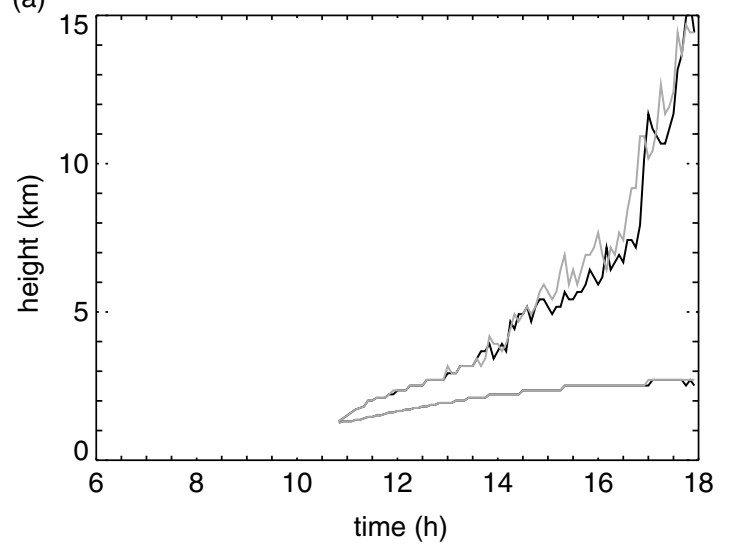

(b)

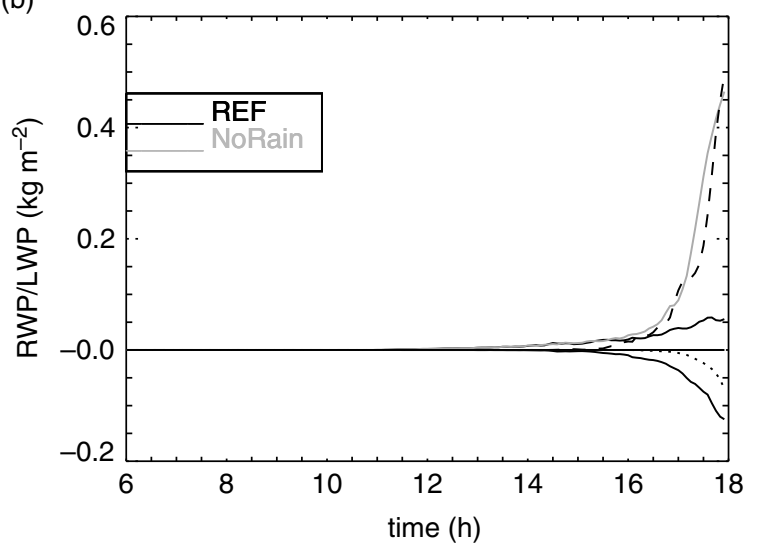

Figure 17. Same as Figure 10 but for REF (black) and NoRain (grey) simulations. In (b), accumulated surface precipitation (is multiplied by -1, dotted line) and integrated content of other hydrometeors (sum of ice, snow and graupels, dashed line) are also plotted.

(a)

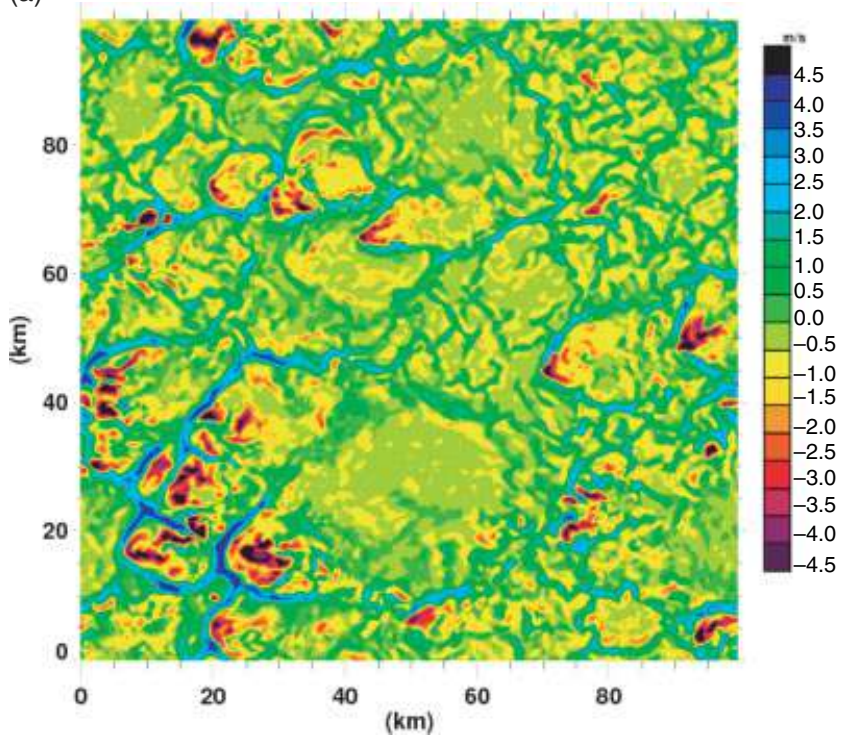

(b)

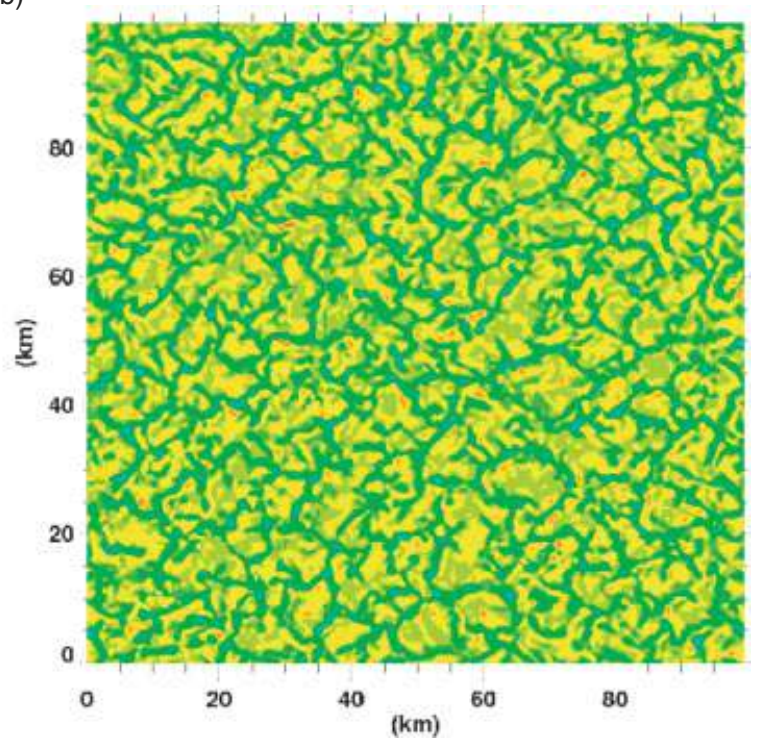

Figure 18. Horizontal cross-section of the vertical velocity at $600 \mathrm{~m}$ above ground level in (a) REF and (b) NoRain simulations.

the formation of rain strongly modifies the boundary layer. Nevertheless, in sharp contrast with the results of KR06, for this semi-arid case, characterized by higher surface sensible heat fluxes and a weaker lapse rate, the formation of cold pools is not required to get deep convection to initiate.

In conclusion, the results of these sensitivity tests are in line with findings from previous studies regarding the significance of environmental moisture and stability; namely convective initiation is favoured for moister and less stable conditions. They have highlighted the subtle role of the wind shear and, more perhaps surprisingly, a weak sensitivity of the onset of deep convection to rain processes, despite a large impact of evaporatively driven downdrafts on the boundary layer. Finally, these tests have underlined that in semi-arid regions a large sensible heat flux is a necessary condition for convection and that cold pools are not required for deep convection to initiate.

\subsection{Shallow cumulus and deep convection initiation criteria}

The onset of convection (shallow and deep) can be used to test the behaviour of parametrizations. Here, we evaluate different criteria currently used in the parametrizations of convection to assess the time of initiation of shallow and deep convection. The reference for initiation of shallow convection is the time when the maximum cloud depth reaches $150 \mathrm{~m}$. One criterion to detect the start of cumulus can be based on LCL and assumes that shallow convection is triggered as soon as LCL and the boundary layer height are similar (here considered within $100 \mathrm{~m}$ ). This criterion predicts the cumulus onset about $1-2 \mathrm{~h}$ too late (Figure 19). This underlines the role of thermals overshooting the mean boundary layer height and reaching LCL, in agreement with Zhu and Albrecht (2003).

Two kinds of criteria used to detect the start of deep convection are tested here: criteria based on geometrical considerations and criteria based on thermodynamical considerations. In this section, we use as a reference the time when the maximum cloud depth has reached $8000 \mathrm{~m}$ (these values are reported in Table III). Note that there is very little sensitivity to the threshold used for the maximum cloud depth. Another criterion, based on geometry, is that of $\mathrm{Wu} 09$, based on the increase in the growth of the centre of the cloud layer. This criterion correctly predicts the transition to deep convection for all the simulations as shown in Figure 19. The traditionally used criteria based on thermodynamical 


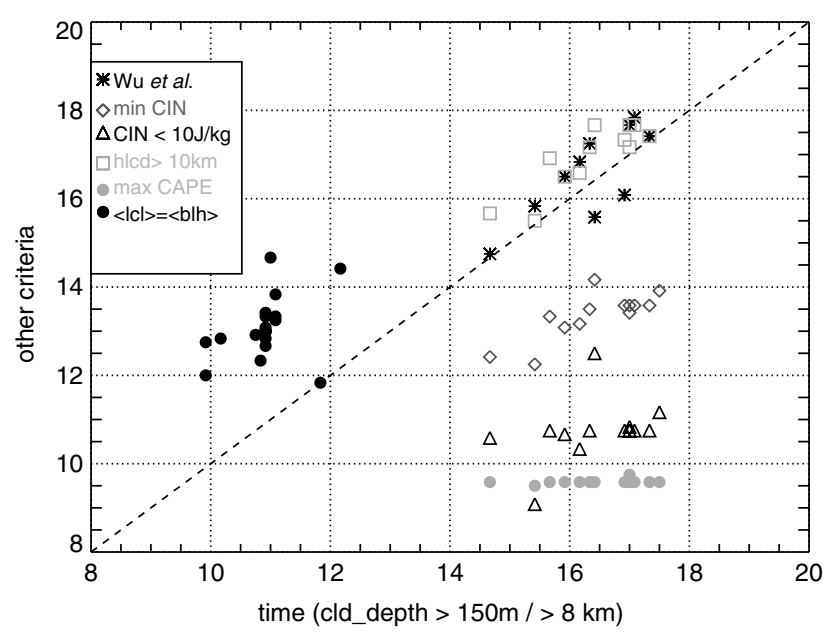

Figure 19. Evaluation of criteria predicting shallow convection initiation (time when average LCL equals average boundary layer height is plotted as a function of the time when maximum cloud depth reaches $150 \mathrm{~m}$, black dots) and deep convection initiation according to different criteria: maximum of CAPE (grey dots), CIN $<10 \mathrm{~J} \mathrm{~kg}^{-1}$ (black triangles), minimum of CIN (grey diamonds), Wu09 criterion (stars) and maximum cloud depth reaching $10000 \mathrm{~m}$ (grey squares) are plotted as a function of the time when maximum cloud depth reaches $8000 \mathrm{~m}$ for all simulations presented in the previous section.

considerations are the maximum of CAPE, the minimum of CIN or the minimum of the normalized saturation deficit (NSD, Chaboureau et al., 2004). The maximum of CAPE is not a relevant criterion for this case; the minimum of CIN is a better criterion even though if one fixes a threshold it has to be very low, as a threshold of $10 \mathrm{~J} \mathrm{~kg}^{-1}$ predicts initiation $4 \mathrm{~h}$ too early compared to the minimum of CIN (Figure 19). The NSD criterion predicts the transition about $2 \mathrm{~h}$ too early (not shown). The minimum of CIN is the only thermodynamical criterion to predict correctly the variation of convective initiation time -between the different cases, even though biased by about $2 \mathrm{~h}$ too early.

\section{Conclusion}

In this study the results of a high-resolution threedimensional simulation of initiation of daytime convection in a semi-arid environment are presented and discussed. This case has been well documented during the AMMA field campaign, since the initiation of convection took place within the scope of radar and in the vicinity of an intensely instrumented site. It allows an evaluation of various aspects of the simulations against observations. An observationally based framework to study daytime convection in a semiarid environment is proposed. It corresponds to a commonly used framework used for parametrization development, as the set-up described in this paper can be used for SCM simulations. In particular, the case is expected to further help in investigating the issue of representation of the diurnal cycle of convection by parametrizations in semiarid conditions, which have been rather overlooked until now. The present study highlights how the characteristics of convective initiation over semi-arid lands contrast with those encountered in moister conditions (different time evolution of convective indexes) and this raises new challenges for modelling.

A high-resolution three-dimensional simulation has been evaluated against available observations and it is found to provide a realistic depiction of the evolution of the boundary layer (height and thermodynamic structure) and of cloud development. Sensitivity tests of the resolution and size of the domain have indicated that the selected choices were relevant. The apparent heat source and moisture sink have been quantified and indicates that such small system significantly contributes to the vertical transfer of heat and moisture. Finally, sensitivity tests to initial and boundary conditions have shown that, in a semi-arid environment also, convection initiation is sensitive to the atmosphere stability and moisture, in agreement with previous studies focused on the wet Tropics and midlatitudes. Moreover, it is shown that in such conditions cold pools are not needed for initiation of convection but it is required to have a large sensible heat flux to ensure a sufficiently high boundary layer and energy.

Finally, recent studies point to the significance of surface heterogeneities for the triggering of convection in such semiarid conditions (e.g. Gounou, 2011; Taylor et al., 2011). In the future, we plan to study this issue further by introducing realistic surface patterns and exploring the role of explicitly simulated mesoscale circulations induced by these surface heterogeneities.

\section{Acknowledgements}

Based on a French initiative, AMMA was built by an international scientific group and is currently funded by a large number of agencies, in particular from France, UK, USA and Africa. It has been the beneficiary of a major financial contribution from the European Community's Sixth Framework Research Programme. The authors are grateful to M. Koehler, M. Chong, B. Campistron and F. Flavot.

\section{References}

Agusti-Panareda A, Beljaars A, Ahlgrimm M, Balsamo G, Bock O, Forbes R, Ghelli A, Guichard F, Kohler M, Meynadier R, Morcrette JJ. 2010. The ECMWF re-analysis for the AMMA observational campaign. Q. J. R. Meteorol. Soc. 136: 1457-1472.

Alonge C, Mohr KI, Tao WK. 2007. Numerical studies of wet versus dry soil regimes in the West African Sahel. J. Hydrometeorol. 8: 102-116.

Betts AK, Jakob C. 2002. Study of diurnal cycle of convective precipitation over Amazonia using a single column model. J. Geophys. Res. Atmos. 107: 4732, DOI: 10.1029/2002JD002264.

Bouniol D, Couvreux F, Guichard F, Kamsu-Tamo P-H, Leplay D, O'Connor E. 2011. Documentation of cloud diurnal and seasonal cycle in Niamey (Niger). J. Appl. Meteorol. in press.

Canut G, Lothon M, Said F, Lohou F. 2010. Observation of entrainment at the interface between monsoon flow and the Saharan Air Layer. Q. J. R. Meteorol. Soc. 136: 34-46.

Chaboureau JP, Guichard F, Redelsperger JL, Lafore JP. 2004. The role of stability and moisture in the diurnal cycle of convection over land. Q. J. R. Meteorol. Soc. 130: 3105-3117.

Comer RE, Slingo A, Allan RP. 2007. Observations of the diurnal cycle of outgoing longwave radiation from the Geostationary Earth Radiation Budget instrument. Geophys. Res. Lett. 34: 1-5.

Couvreux F, Guichard F, Redelsperger J-L, Kiemle C, Masson V, Lafore JP, Flamant C. 2005. Assessment of water vapour variability within a convective boundary layer over land using large eddy simulations and IHOP observations. Q. J. R. Meteorol. Soc. 131: 2665-2693.

Couvreux F, Guichard F, Masson V, Redelsperger JL. 2007. Negative water vapour skewness and dry tongues in the convective boundary layer: observations and large-eddy simulation budget analysis. Bound.Lay. Meteorol. 123: 269-294.

Crook NA. 1996. Sensitivity of moist convection forced by boundarylayer processes to low-level thermodynamic fields Mon. Weather Rev. 124: $1767-1785$.

Cuxart J, Bougeault P, Redelsperger JL. 2000. A turbulence scheme allowing for mesoscale and large-eddy simulations. Q. J. R. Meteorol. Soc. 126: 1-30. 
Derbyshire SH, Beau I, Bechtold P, Grandpeix J-Y, Piriou JM, Redelsperger J-L, Soares PMM. 2004. Sensitivity of moist convection to environmental humidity. Q. J. R. Meteorol. Soc. 130: 3055-3079.

Findell KL, Eltahir EAB. 2003. Atmospheric controls on soil moisture boundary layer interactions. Part I: framework and development $J$. Hydrometeorol. 4: 552-569.

Gounou A. 2011. The driving processes behind the diurnal cycles of the West African Monsoon. University of Paul Sabatier: Toulouse.

Goutorbe JP, Noilhan J, Lacarrere P, Braud I. 1997. Modelling of the atmospheric column over the central sites during HAPEX-Sahel. J Hydrol. 189: 1017-1039.

Grabowski WW, Bechtold P, Cheng A, Forbes R, Halliwell C, Khairoutdinov M, Lang S, Nasuno T, Petch J, Tao WK, Wong R Wu X, Xu KM. 2006. Daytime convective development over land: a model intercomparison based on LBA observations. Q. J. R. Meteorol. Soc. 132: 317-344.

Guichard F, Lafore J-P, Redelsperger J-L. 1997. Thermodynamical impact and internal structure of a tropical convective cloud system. Q. J. R. Meteorol. Soc. 123: 2297-2324.

Guichard F, Petch JC, Redelsperger JL, Bechtold P, Chaboureau JP, Cheinet S, Grabowski W, Grenier H, Jones CG, Kohler M, Piriou JM Tailleux R, Tomasini M. 2004. Modelling the diurnal cycle of deep precipitating convection over land with cloud-resolving models and single column models. Q. J. R. Meteorol. Soc. 130: 3139-3172.

Houston AL, Niyogi D. 2007. The sensitivity of convective initiation to the lapse rate of the active cloud-bearing layer. Mon. Weather Rev. 135: 3013-3032.

Janicot S, Thorncroft CD, Ali A, Asencio N, Berry G, Bock O, Bourles B, Caniaux G, Chauvin F, Deme A, Kergoat L, Lafore JP, Lavaysse C, Lebel T, Marticorena B, Mounier F, Nedelec P, Redelsperger JL, Ravegnani F, Reeves CE, Roca R, de Rosnay P, Schlager H, Sultan B, Tomasini M, Ulanovsky A. 2008. Large-scale overview of the summer monsoon over West Africa during the AMMA field experiment in 2006. Ann. Geophys. 26: 2569-2595.

Janowiak JE, Dagostaro VJ, Kousky VE, Joyce RJ. 2007. An examination of precipitation in observations and model forecasts during NAME with emphasis on the diurnal cycle. J. Climate 20: 1680-1692.

Kang IS, Jin K, Wang B, Lau KM, Shukla J, Krishnamurthy V, Schubert SD, Wailser DE, Stern WF, Kitoh A, Meehl GA, Kanamitsu M, Galin VY, Satyan V, Park CK, Liu Y. 2002. Intercomparison of the climatological variations of Asian summer monsoon precipitation simulated by 10 GCMs. Clim. Dynam. 19: 383-395.

Khairoutdinov M, Randall D. 2006. High-resolution simulation of shallow-to-deep convection transition over land. J. Atmos. Sci. 63 3421-3436.

Kuang Z, Bretherton C. 2006. A mass flux scheme view of a highresolution simulation of transition from shallow to deep cumulus convection. J. Atmos. Sci. 63: 1895-1909.

Lafore JP, Stein J, Asencio N, Bougeault P, Ducrocq V, Duron J, Fischer C, Hereil P, Mascart P, Masson V, Pinty JP, Redelsperger JL, Richard E, Vila-Guerau de Arellano J. 1998. The Meso-NH atmospheric simulation system. Part 1: Adiabatic formulation and control simulations. Ann. Geophys. 16: 90-109.

Lothon M, Said F, Lohou F, Campistron B. 2008. Observation of the diurnal cycle in the low troposphere of West Africa. Mon. Weather Rev. 136: 3477-3500.

Lothon M, Campistron B, Chong M, Couvreux F, Guichard F, Rio C, Williams E. 2011. Life cycle of a mesoscale circular gust front observed by a C-band Doppler radar in West Africa Mon. Weather Rev. 139: $1370-1388$.

Mathon V, Laurent H, Lebel T. 2002. Mesoscale convective system rainfall in the Sahel. J. Appl. Meteorol. 41: 1081-1092.

Miller RL, Slingo A, Barnard JC, Kassianov E. 2009. Seasonal contrast in the surface energy balance of the Sahel. J. Geophys. Res. Atmos. 114 $1-19$.

Mohr KI. 2004. Interannual, monthly, and regional variability in the wet season diurnal cycle of precipitation in sub-Saharan Africa. J. Climate 17: $2441-2453$
Peyrille P, Lafore JP. 2007. An idealized two-dimensional framework to study the West African monsoon. Part II: Large-scale advection and the diurnal cycle. J. Atmos. Sci. 64: 2783-2803.

Piriou JM, Redelsperger JL, Geleyn JF, Lafore JP, Guichard F. 2007. An approach for convective parameterization with memory: Separating microphysics and transport in grid-scale equations. J. Atmos. Sci. 64: 4127-4139.

Ramier D, Boulain N, Cappelaere B, Timouk F, Rabanit M, Lloyd CR, Boubkraoui S, Metayer F, Descroix L, Wawrzyniak V. 2009. Towards an understanding of coupled physical and biological processes in the cultivated Sahel. 1. Energy and water. J. Hydrol. 375: 204-216.

Redelsperger J-L, Sommeria G. 1986. Three-dimensional simulation of a convective storm: sensitivity studies on subgrid parameterization and spatial resolution. J. Atmos. Sci. 43: 2619-2635.

Redelsperger JL, Thorncroft CD, Diedhiou A, Lebel T, Parker DJ, Polcher J. 2006. African monsoon multidisciplinary analysis: an international research project and field campaign. Bull. Am. Meteorol. Soc. 87: 1739.

Reed RJ, Norquist DC, Recker EE. 1977. Structure and properties of African wave disturbances as observed during phase III of GATE. Mon. Weather Rev. 105: 317-333.

Rio C, Hourdin F, Grandpeix J-Y, Lafore J-P. 2009. Shifting the diurnal cycle of parameterized deep convection over land. Geophys. Res. Lett. 36: $1-5$.

Siebesma AP, Cuijpers JWM. 1995. Evaluation of parametric assumptions for shallow cumulus convection. J. Atmos. Sci. 52: 650-666.

Takemi T, Satomura T. 2000. Numerical experiments on the mechanisms for the development and maintenance of long-lived squall lines in dry environments. J. Atmos. Sci. 57: 1718-1740.

Takemi T, Yasui M, Zhou JX, Liu LC. 2006. Role of boundary layer and cumulus convection on dust emission and transport over a midlatitude desert area. J. Geophys. Res. Atmos. 111: D11203, DOI: 10.1029/2005JD006666.

Taylor CM, Ellis RJ, Parker DJ, Burton RR, Throncroft CD. 2003. Linking boundary-layer variability with convection: a case-study from JET2000, Q. J. R. Meteorol. Soc. 129: 2233-2253.

Taylor CM, Harris PP, Parker DJ. 2010. Impact of soil moisture on the development of a Sahelian mesoscale convective system: a case-study from the AMMA Special Observing Period. Q. J. R. Meteorol. Soc. 136: 456-470.

Taylor CM, Gounou A, Guichard F, Harris P, Ellis RJ, Couvreux F, De Kauwe M. 2011. Frequency of Sahelian storm initiation doubled over mesoscale soil moisture patterns. Nature Geosci. 4: 430-433.

Tompkins AM. 2001. Organization of tropical convection in low vertical wind shears: the role of cold pools. J. Atmos. Sci. 58: $1650-1672$.

Weckwerth TM, Parsons DB. 2006. A review of convection initiation and motivation for IHOP_2002. Mon. Weather Rev. 134: 5-22.

Weckwerth TM, Horst TW, Wilson JW. 1999. An observational study of the evolution of horizontal convective rolls. Mon. Weather Rev. 127: 2160-2179.

Weckwerth TM, Murphey HV, Flamant C, Goldstein J, Pettet CR. 2008. An observational study of convection initiation on 12 June 2002 during IHOP_2002. Mon. Weather Rev. 136: 2283-2304.

Wilson JW, Schreiber WE. 1986. Initiation of convective storms at radarobserved boundary-layer convergence lines. Mon. Weather Rev. 114: 2516-2536.

Wu CM, Stevens B, Arakawa A. 2009. What controls the transition from shallow to deep convection? J. Atmos. Sci. 66: 1793-1806.

Yang G, Slingo J. 2001. The diurnal cycle in the Tropics. Mon. Weather Rev. 129: 784-801.

Zhang YY, Klein SA. 2010. Mechanisms affecting the transition from shallow to deep convection over land: inferences from observations of the diurnal cycle collected at the ARM Southern Great Plains site. J. Atmos. Sci. 67: 2943-2959.

Zhu P, Albrecht B. 2003. Large eddy simulations of continental shallow cumulus convection. J. Geophys. Res. Atmos. 108: 1-18. 